\title{
A STUDY OF PORTABLE VIBRATING TOOLS IN RELATION TO THE CLINICAL EFFECTS WHICH THEY PRODUCE
}

\author{
BY \\ JOHN N. AGATE and H. A. DRUETT \\ From the Department for Research in Industrial Medicine (Medical Research Council), \\ The London Hospital
}

(RECEIVED FOR PUBLICATION, JANUARY 22, 1947)

\begin{abstract}
During the recent war the clinical effects of the use of vibrating machinery have come even more to the fore than previously. This is because production methods, particularly in the aircraft industry, have required the increased use of portable grinding and riveting tools. Loriga (1911) first connected circulatory disturbances with the use of pneumatic tools, which had by then been in favour for many years. - Pioneer work has been done by Alice Hamilton (1918), also by Rothstein and others (1918), and since then the historical facts have been described by several authors, notably Hunter and others (1945), Gurdjian and Walker (1945), and Dart (1946), so that a general survey of the literature would be of little advantage here. It is, nevertheless, worth while to consider certain tendencies in recent papers on the subject. In earlier years the reported series dealt with the effects of pneumatic tools of various kinds; in only one instance, that of " pounding up" machines (described by Middleton in 1930), which were used in the boot and shoe industry and which soon went out of use, was any other type of vibrating machine involved. The lesions brought about by pneumatic tools were : (a) injuries to joints ; $(b)$ injuries to muscles, fasciæ, and peripheral nerves ; and (c) Raynaud's phenomenon, which occurred in the hands. Of late other ways of working have produced similar clinical manifestations, and this is not surprising in view of the widespread use in modern industry of machines which produce noise and vibrations, and the demands for ever-increasing output. Telford and others (1945) discussed Raynaud's phenomenon, which occurred in those who handled portable rotary grinding tools. Agate, Druett, and Tombleson (1946) likewise reported it occurring in those who ground small iron castings against large belt-
\end{abstract}

driven grinding wheels. In this instance there was no vibrating tool, but the castings were firmly held in the fingers and vibrated whilst being ground.

Dart (1946) and Peters (1946) have found a rather different clinical picture in those who use a light high-speed rotary grinding-tool driven by an air turbine. In their series of cases, the symptoms consisted of pain, numbness, stiffness, and swelling, and these predominated over the physical signs, which appeared to be variable and indefinite. They did not observe the periodical blanching of the fingers in response to cold, which is the main feature of vascular disturbances hitherto reported. Gurdjian and Walker (1945) add to the earlier reports on pneumatic tools a series of six cases of Raynaud's phenomenon occurring in those who had used a light portable riveting hammer in one hand while they steadied the work with the other; the industry was aircraft construction, the affected hand was that which held the work and not the one which held the tool, and all the sufferers were women.

The published work on vascular disturbances of occupational origin clearly demonstrates that vibration is a factor common to all outbreaks. The hardness of the materials worked upon has been mentioned-Seyring (1930), while Alice Hamilton (1918) and Bridge and Middleton (1925) thought that the excessive strength of the men's grip ought to be considered. At first the physical characteristics of the vibrations attracted little notice, but Leake (1918) had estimated the primary vibrations from limestone cutting tools at 3,000 to 3,500 per minute, with subsidiary vibrations up to 10,000 per minute. Gerbis and others (1931) found that tools in the shoe trade were responsible for vibrations of 17,000 to 36,000 per minute, or 280 to 600 per second, and they produced Raynaud's 
phenomenon very rapidly. Hunt (1936) stated that the riveting hammer causing his cases worked at 2,300 strokes per minute and weighed $13 \mathrm{lb}$. McLaren (1937) suggested that the same frequency was critical, but some of his men had acquired the disease from tools of different speeds ; these speeds were not stated. Cummins (1940) quoted the same figure, and alleged that tool speeds beyond 2,300 strokes per minute were hazardous. Mills (1942) thought tools at 3,000 strokes per minute were more likely to produce lesions than those at slower rates. The evidence for some of these statements does not appear to be complete.

The women in the series of Gurdjian and others (1945) worked with 3-lb. pneumatic hammers of 3,000 to 3,400 strokes per minute, which is a higher critical frequency than some previous authors allow. Hunter and others (1945) studied groups of men using tools of different speeds on different jobs, and, from the relative incidence of disease in each group, suggested that tool speeds of 2,000 to 3,000 strokes per minute would be best avoided. Their suggestion, and our own experience of cases resulting from the tools described by Telford and others (1945), in which a rotation speed of 2,900 revolutions per minute is mentioned, has prompted us to make a closer study of the vibrations themselves.

Besides the frequency, it is necessary to study the amplitude and form of the vibrations, and to recognize that few except of the simplest kind are in the form of pure " notes," depictable graphically as sine wave curves. Most have complex wave forms which can conveniently be expressed in terms of a fundamental frequency of large amplitude, upon which are imposed various harmonics of progressively higher frequency and smaller amplitude. Peters (1946) mentions that engineers had estimated at 0.001 to 0.002 in. $n$ the amplitude of the vibrations arising from the use of special high-speed tools working at about 2,500 revolutions per minute; but their method of determining this is not stated. Dart (1946), describing the same series, briefly writes of an attempt to use a cathode-ray oscillograph to study frequencies and amplitudes. The method later had to be abandoned, but a rate of 12,000 vibrations per minute, and an amplitude of $0.003 \mathrm{in}$. is mentioned in his paper.

A tool may be said to have a speed of so.many strokes or revolutions per minute (r.p.m.). This figure will determine the fundamental frequency of the vibration, but it is not justifiable to assume that this is the damaging one. It is already recognized that the biological effects of high-frequency sounds, or high-frequency alternating currents, are different from those of lower ones. We have outlined a method (Agate and Druett, 1946) for rapidly recording vibrations in terms of the frequency and amplitude of all the individual harmonics. Briefly, the method depends upon placing a crystal pick-up on the vibrating surface and putting the electrical response which it generates through a series of filters, so that the fraction in each frequency band appears quantitatively upon a fluorescent cathoderay screen and can be photographed and measured. The analysing instrument is an adaptation of an acoustic spectrometer. The frequency and size of the harmonics can, within certain limits, be calculated in terms of cycles per second, and millimetres (or microns) respectively. We found that the technique can be used for any sort of vibrating machine, whether piston-operated or rotary, and even when the type of vibration changed from moment to moment. This was so in the study of the grinding of small castings, where the first results by the present authors' method were reported. The crystal pick-up in a special mounting can lie under the hand, and it responds to vibrations at right angles to its flat surface, so it can record the actual vibration likely to impinge on the surface of the hand in various circumstances.

\section{The Present Investigation}

The scope of the work was to apply this analytical method to the vibrations coming from a small but fairly representative collection of tools working under normal conditions. First, there might exist a relationship between the type of vibration coming from a tool and the type or incidence of the lesion it produced in patients. Secondly, the effect of different mechanical factors in the design of tools might be judged. Thirdly, the relative merits of different methods of doing the same piece of engineering work could be weighed up ; and, fourthly, a trial could be made of the efficacy of various absorbent materials which had already been suggested for preventing the vibrations from reaching the hands.

The tools examined fell naturally into two classes, regardless of the motive power they used. First, there were those which depended for their effectiveness upon the to-and-fro motion of a piston. The majority of compressed-air tools are of this kind, for example rock drills, road rippers, mechanical picks, riveting and chipping hammers, and scaling hammers. There are a few similar tools, driven electrically, in which the oscillation is set up by an eccentrically placed weight, but we did not have an opportunity to examine this type ; it is unlikely to differ much from the air-driven machines. In all these types a succession of hammer blows is the 
method of work, and vibration is inevitable. Moreover, the vibration is not so much a continuous oscillation, as a series of short pulses with relatively long pauses between them. Rock drills can be included in this group, though their action is double ; the piston oscillates to and fro, but also rotates a certain distance with each stroke. The tool steel thus has an intermittent rotary motion supplemented by hammer blows. Its effective action is one of continuous, slow boring into hard rock, and the whole rock drill might not be expected to vibrate to and fro to the same extent as a road ripper or pneumatic pick, despite the fact that there is within it a heavy oscillating piston.

The second group of tools comprises those which rotate and are held in the hands, such as polishing and grinding equipment, whether these are driven by air turbine, by portable electric motor incorporated in the tool, or by a flexible cable passing from a fixed motor to the handpiece. Vibration is not essential to the effective working of these tools ; the better they are made, the less there is, although when they are used for grinding vibration is inevitable.

\section{PISTON-OPERATED TOOLS}

\section{Introduction}

The suggestion of Hunter and others (1945) that the critical damaging frequency for these tools lies between 2,000 and 3,000 strokes per minute is probably true, but the problem can be looked at from other points of view. Tools of this kind are constructed to work at from 1,000 to 8,000 beats per minute (b.p.m.), but the rate varies inversely with the size and weight of the tool and with the heaviness of the job to be done. A light-weight riveting hammer of from 3,000 to 8,000 b.p.m. is used for small cold rivets and can be held in the hands with ease. A heavy road ripper weighing $75 \mathrm{lb}$. may work at only 1,000 to 1,200 b.p.m. Certain of the hand-operated rock drills weigh from 30 to $56 \mathrm{lb}$. and work at 1,750 to 2,300 b.p.m., and all these larger tools are usually used pointing downwards ; the weight of the tool does the work, and the man must lean his own weight on the handles in addition ; but while it is held vertically he need not maintain the same continuously powerful grip that he would use in supporting the tool in the horizontal position. The strength of the man's grip was called in question some time ago (Alice Hamilton, 1918). It is significant that relatively few cases of Raynaud's phenomenon have been reported from men working with these slower, heavier road rippers and drills working downwards; we did not hear of any in the course of our inquiries. But the position is very different in the case of riveting hammers and pneumatic chisels of various sorts. These have to be held horizontally, the physical work is done by the weight of the man's body lunging forward, and the tool is held up only by the strength of his grip. The weight of such tools is of the order of 12 to 20 lb. The vibration resulting from this kind of work is intense and almost painful, as anyone may discover who tries it. It is found also that tools of this size most often work at 1,700 to 3,500 b.p.m. (though a few are rated at 1,050 and others at 6,000 b.p.m.).

Before the tool speeds of 2,000 to 3,000 per minute are incriminated, it is well also to remember that these frequencies are the ones usually selected for work which is particularly arduous, which requires a specially firm continuous grip, and which is associated with the most intense vibration. Riveting is typical of such work. Hunter and others stated that 53.5 per cent. of riveters working at 2,000 b.p.m. had " white fingers," compared with 74 per cent. of a group working at 2,000 to 3,000 b.p.m. Their tables showed, of the latter group, that 20 out of 27 (74 per cent.) had done the work for between 11 and 20 years or more, whereas in the former group 22 out of 43 ( 51 per cent.) had worked there less than 10 years. Had the duration of the work been the same in both series, the incidence of the disease might have been more equal, for it has several times been pointed out that the longer a man works in this way the greater his chance of developing Raynaud's phenomenon (Seyring, 1930 ; Agate, Druett, and Tombleson, 1946).

We were allowed, through the courtesy of a firm of pneumatic tool manufacturers, to experiment upon their models then in production. The tools were handled by experienced men, and records were taken with the tools working for the most part upon the materials for which they were designed. Rock drills and road rippers were worked on granite blocks, pneumatic chisels and chippıng hammers were made to cut steel plate, and riveting hammers were tested while forming hot steel rivets in thick armour plate. As already stated, the larger the pneumatic tool, the slower is its rate of working. Many of those studied were working at rates well below 2,000 b.p.m., though the rates were not exactly those given in the specifications, owing to changes in the pressure of the air supply and the amount of muscular force being applied. We found that a modification of the original analytical method was necessary, because our acoustic spectrometer was not designed to record at frequencies lower than 40 cycles per second $(2,400$ per minute). Readings were therefore taken as usual on the spectrometer to find the higher harmonics, but the fundamental was calculated by passing the pick-up response into a double-beam cathode-ray oscillograph, comparing the " trace" on the screen with that simultaneously produced by 50 -cycle alternating current, and photographing the screen. The filme were enlarged, and pictures (fig. 1) 


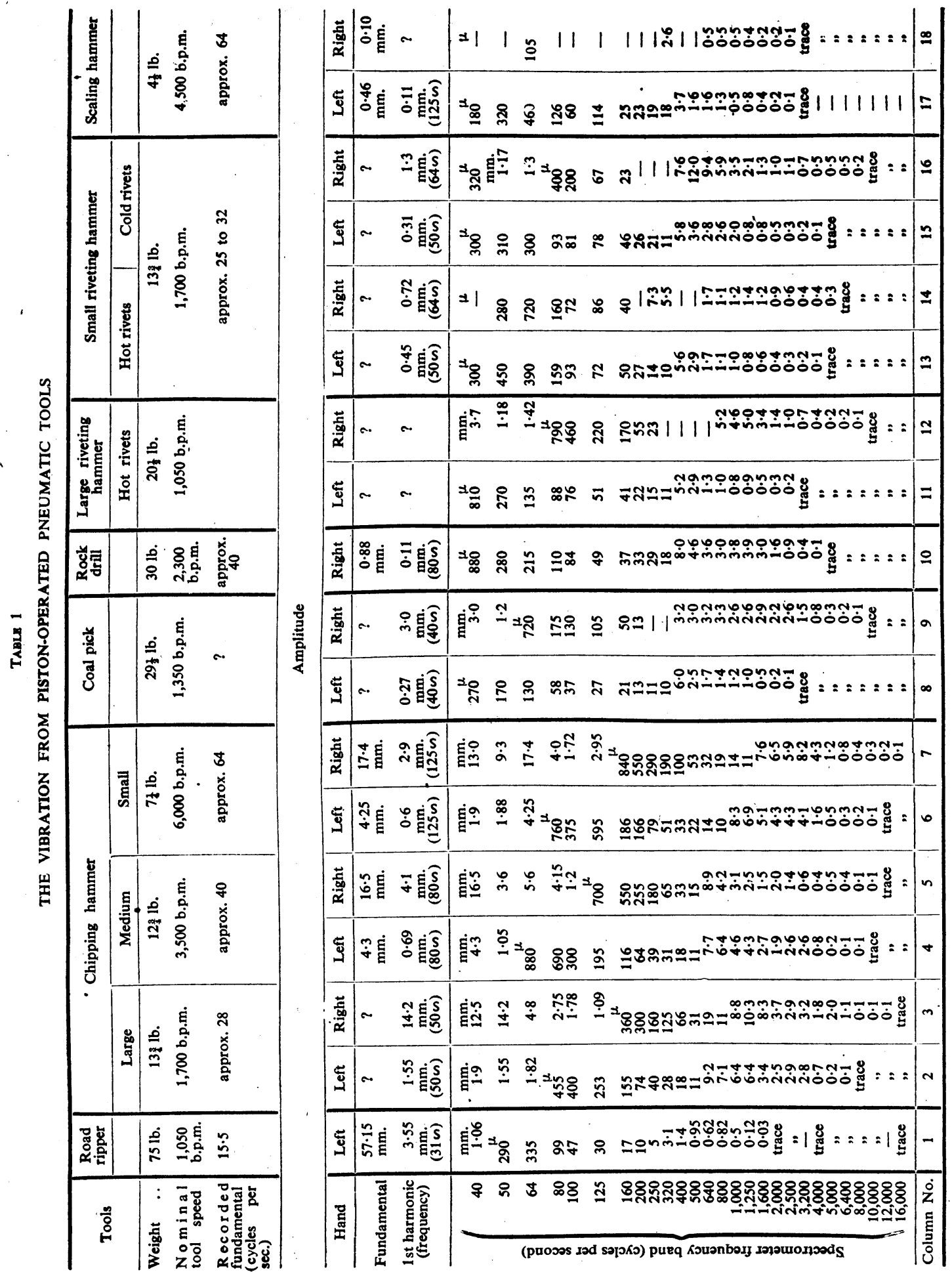


PORTABLE VIBRATING TOOLS

एᄆ
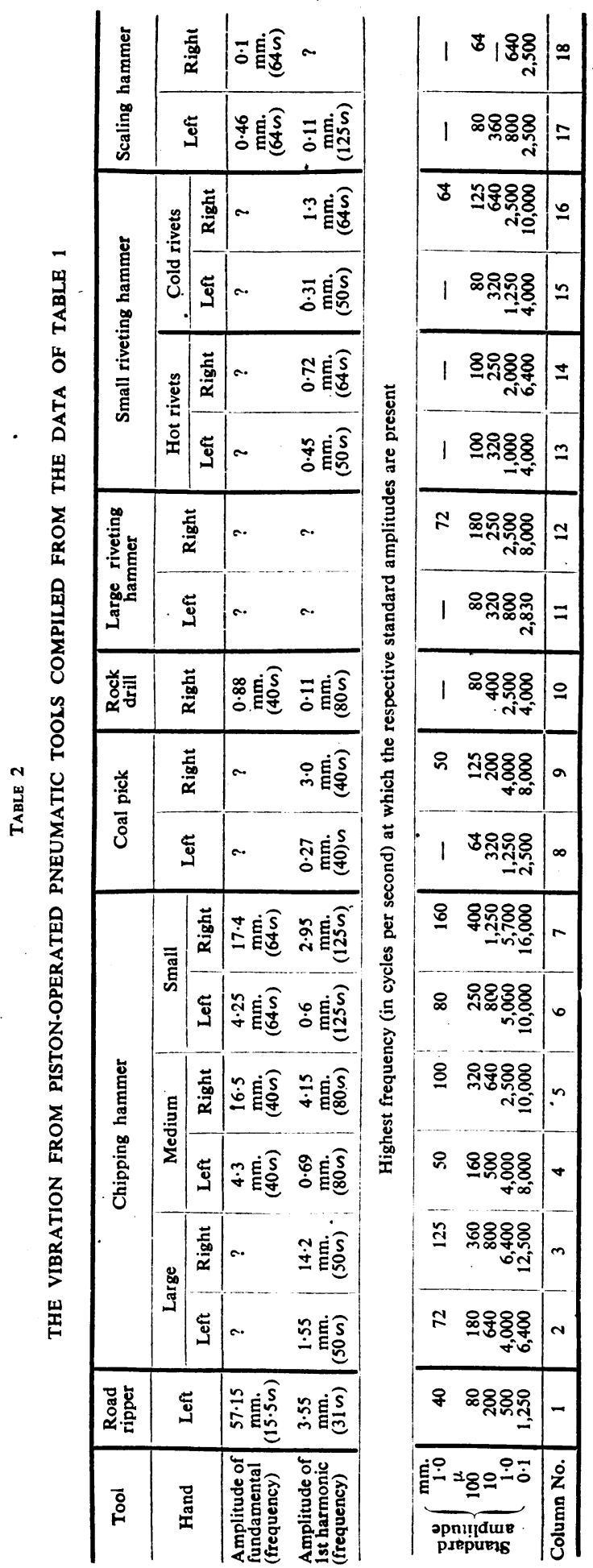

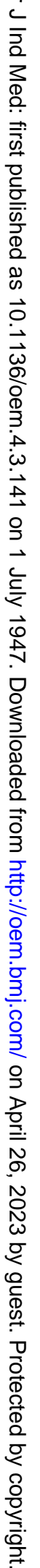


were produced which enabled the frequency to be read off ; then, after computation of the Fourier series by 24 ordinates, the amplitude of the fundamental and the first few harmonics could be calculated.

\section{The Grip Used on the Piston-operated Pneumatic Tools}

To interpret the results it is necessary to know how each tool is handled, so for ease of description let it be assumed that all the workers are right-handed and hold the tools in the most usual way. Road rippers and rock drills (figs. 2 and 3) are most often used with the operator leaning his weight upon the double handle, with his arms straight, both wrists fully dorsi-flexed, and the fingers gripping on the handles, which are usually covered with firm rubber. The tool "steel" drills a hole in which the machine can stand upright by itself, so that for most of the time the grip need not be as strong as would be needed for weight lifting. The shock is borne directly across the palms and at right angles to their surface. Pneumatic coal picks (fig. 4) are usually provided with a single handle at the base, which is held in the right hand. Such a tool is used in all positions, and the worker steadies the thick barrel at its mid-point on the front of his left hand and fingers, but the main shock is borne by the right hand which is transmitting the weight of his body. Riveting and chipping hammers (figs. 5 and 6 ) are held much as a pick is held, but they are usually worked horizontally, and the hands have to steady the tool and support its weight. The right hand holds the pistol grip and is subjected to the whole force of a to-and-fro vibration which travels along the long axis of the tool. The left hand grips near the working end, or on the tool steel itself, and it is subjected to vibration in all directions, though the main to-and-fro vibration does not impinge at right angles to the palm and fingers, but instead exerts a rolling action from side to side. The vibration pick-up was in all cases placed at the point where most pressure would be applied ; that is, when under the right hand it recorded the principal displacement to and fro, and when under the palm of the left hand it recorded the general vibration and "chatter" in directions at right angles to the first. When a scaling hammer (fig. 7) is used, the cutting steel works in and out at right angles to the long axis of the tool ; the left hand presses it against the surface to be scaled, and therefore absorbs the main vibration, whereas the right hand in this case merely steadies the end and the compressed air hose.

\section{The Results Recorded from Piston-Operated Pneumatic Tools}

The results recorded from piston-operated pneumatic tools are shown in Table 1. This table records the amplitudes in millimetres or microns at the various frequencies which make up the complete spectrum as far as 16,000 cycles per second. But from these columns of 27 values, which diminish at different rates and which show maximum values at different points, it is not always easy to decide on the severity of the total vibration, nor is it even easy to say whether one tool is better or worse than another. Table 2 has therefore been constructed to make interpretation easier. It is based upon the supposition that a vibration, for example, of 30 microns at 1,000 cycles is more severe than one of 30 microns at 100 cycles, for the energy involved in a vibration (that is, the potential damaging force) depends on the product of the amplitude squared and the frequency squared. Table 2 records the highest frequency at which an amplitude of 1 millimetre, $0 \cdot 1$ millimetres, 10 microns, 1.0 microns, and 0.1 microns respectively was present. These will be referred to henceforward as "standard amplitudes." Approximations had to be made throughout, and where figures fell well between two frequencies, the mean of the two was taken. A set of high figures in Table 2 indicates that relatively large amplitudes were present at high frequencies, and therefore that the vibration is intense. Consideration of each column, and at the same time of the size of the larger (i.e. fundamental) amplitudes, appears to give a reasonable picture of the conditions set up by each tool. By this means the tools may be placed in order of the hazard they might reasonably produce, but strict quantitative comparison between them must be made only with great caution.

The Road Ripper.--This tool (fig. 2) was the standard model and is commonly used all over the country for road-breaking operations. It was driven downwards into a block of granite, but its steel was specially blunted so that conditions could be kept constant longer than would have been the case if the block had been broken up with a sharp steel. The weight was $75 \mathrm{lb}$., and the designed speed was 1,050 b.p.m., so that the fundamental frequency should have been 17.5 cycles per second. In fact, it was 15.5 cycles per .second, and at this frequency the enormous amplitude of $57 \cdot 15 \mathrm{~mm}$. was present. At 40 cycles $1.0 \mathrm{~mm}$. was present ; $100 \mu$ appeared as high as at 80 cycles, $10 \mu$ at 200 cycles, $1 \mu$ at 500 cycles, and $0 \cdot 1 \mu$ at about 1,250 cycles per second.

A new experimental road ripper was also tested. It appeared to be a considerable improvement on the older model, having lower values at the fundamental and other low frequencies, but $1.0 \mu$ and $0.1 \mu$ amplitude appeared, for all that, higher in the spectrum than with the previous type.

The Chipping Hammers (Pneumatic Chisels).-Three machines of this type were tried, weighing $13 \frac{3}{4} \mathrm{lb} ., 12 \mathrm{lb}$., and $71 \mathrm{lb}$., and designed to work at $1,200,3,500$, and 6,000 b.p.m. respectively. For comparison they were all made to work on the same operation, that of cutting $\frac{3}{8}$ in. steel plate, which they did with ease. The small tool (fig. 6) did the work more slowly and set up a very intense vibration, since it was probably being overloaded. It should be noted from the tables that the two smaller ones had fundamental amplitudes of 16.5 and $17.4 \mathrm{~mm}$. at 40 cycles and 64 cycles respectively. These are formidable figures, and at these frequencies are much 
higher than other tools produce, even if the latter sometimes produce greater amplitudes at lower frequencies. In the case of one of these chisels there was $0 \cdot 1 \mu$ present at the extreme upper end of the recordable spectrum ( 16,000 cycles). In each case the intensity of vibration impinging on the left hand was apparently much less than that on the right. This has already been foreshadowed. When in use these tools need the strongest possible grip to keep them steadily on the job; an inexperienced worker cannot handle them at all.

The Coal Pick.-This type of tool (fig. 4) is extensively used in mines to break coal from the seams. In our experiments it was used horizontally against a granite block, a material which is somewhat harder than that for which it was intended. Its weight was $29 \frac{1}{2} \mathrm{lb}$., and its rate of working 1,350 b.p.m., which should give a fundamental at about 22 cycles per second. The amplitude of the fundamental could not in this case be determined because of the complexity of the wave form, but consideration of the first harmonic suggests that it is comparable with that of the road rippers. The left hand in this case was subjected to much less vibration than from any machine so far considered, while the right hand seemed to be subjected on this tool to about as much as the left hand received from the chipping hammers.

The Rock Drill.-The rock drill chosen was one which would normally be hand-operated (fig. 3). There are many other types of .rock drill, but most of them are supported on steel beams or made to work, as in " stoping," with one end pressed against the surface of the rock, so in neither case would the drill have to be held very firmly in the hands. The chosen tool was used working vertically downwards in its native granite Since it had two similar handles at the base, the effect on each hand was equal, and readings were taken from under the right hand only, at right angles to the long axis of the machine. The crystal was strapped to a standard rubber handgrip on the handle. The weight of the drill was $30 \mathrm{lb}$., the speed 2,300 b.p.m., and the action rotary and boring in type, as already described. The vibrations were relatively small, the fundamental (at approximately 40 cycles per second) was only $0.88 \mathrm{~mm}$. Nowhere was $1.0 \mathrm{~mm}$. recorded, and above 4,000 cycles all appreciable vibration was absent. It was not possible to try this tool without rubber handgrips, so the effect of these is indeterminate.

The Riveting Hammers.-Two riveting hammers were tested under normal conditions. One weighed $13 \frac{3}{4} \mathrm{lb}$. and worked at 1,700 b.p.m. ; the other (fig. 5) weighed $20 \frac{1}{2} \mathrm{lb}$. and worked at 1,050 b.p.m. Unfortunately, no opportunity presented itself for trying out any faster and smaller riveting tools.

All such tools require a very powerful grip for efficient working. Our experiments were done while driving rivets into prepared holes in a steel plate against an automatic pneumatic "holder-up." The rivets were $\frac{3}{4}$ in. in diameter for the smaller hammer, and $1 \frac{1}{8}$ in. for the larger. Experimentally, some were driven while hot and some while cold, but in practice such large rivets would always be driven hot. The nominal fundamental frequencies were 28 cycles and $17 \cdot 5$ cycles, but the records proved too complex for the corresponding amplitudes to be accurately computed. They were obviously high.

It will be seen that the vibration in riveting is not quite so intense as that from chipping hammers, but it is nevertheless large. Riveters, moreover, tend not to be casual labourers but to work with these tools for many years. Cold riveting seems to produce somewhat more vibration than hot riveting, whether judged by the size of the fundamental or by the range; but this is true for the right hand only. In the left hand the figures for hot and cold riveting are equal, to within the limits of experimental error. The contention that there is some significance in the hardness of the material worked upon is only poorly borne out here. In any case, different work on different materials usually requires a different size of tool, and different conditions would apply. As previously, the left hand apparently absorbs less vibration than the right during either hot or cold riveting.

The Scaling Hammer.-This tool (fig. 7) weighed only $4 \frac{1}{2} \mathrm{lb}$. and had a small piston-operated cutting head working at right angles to the long axis of the tool. It worked at 4,500 b.p.m. The left hand would be expected to undergo most disturbance, and this appears so from the figures. The grip needs to be less powerful with this tool than that required for a riveting or chipping hammer. There is less disturbance from a scaling hammer than there is from any other piston-operated tool in the series.

\section{ROTATING TOOLS}

\section{Introduction}

The tool which Telford and others (1945) described is relatively new compared with the pneumatic hammers. It consisted of a handgrip through the centre of which a spindle rotated on ball-bearings. On to this spindle many different kinds of " heads" for cutting, grinding, or polishing metal could be fixed. The driving power came through a flexible covered cable from an electric motor fixed on the bench or suspended from the roof. In such tools the motor may be from $\frac{1}{2}$ to $1 \frac{1}{2}$ horsepower, and there are pulleys which allow of three different spindle speeds. These machines were found to be very useful for cleaning and "burring " aluminium alloy castings and polishing all manner of steel parts for aero engines, and they were used in increasing numbers as the war progressed. Our experience of various makes of these tools led us to think that these differ in detail, but not in principle or application. In the last-mentioned paper the authors stated that the higher rates of revolution, the hardness of the material worked upon, and the bluntness of the cutters were the significant factors responsible for increasing the damaging vibrations. They suggested that the risk of vascular disturbances is probably insignificant if the speed is below 2,000 revolutions per minute (r.p.m.). Theirs, however, 
was a clinical study, and experimental data in support of their contention were lacking. Whitwell (1945), in a published letter, drew attention to many other factors in these tools which require consideration. He pointed out that there are a number of different " heads" of widely different diameters ; there are different speeds; the spindles are of variable length; and the longer the spindle, the greater the "whip" which results. The shaft ought to be kept lubricated and the balance adjusted, and the flexible cable should not be allowed to .kink. He suggested that unskilled men tend to press harder than they need, and allow the tool to jump about in their hands. It was clearly profitable to investigate some of these suggestions experimentally. Also, since the work of Dart (1946) and Peters (1946), who reported from America a new clinical picture from the use of different vibrating rotary tools working at 25,000 r.p.m., there has arisen an even greater need for recording the vibrations produced.

We set out to take records from as many types of rotary drilling, grinding, and polishing tools as were readily available. A few, which we studied at the works where the pneumatic hammers were made, were driven by air turbines. The remainder were collected together in the shops and the experimental vibration laboratories of an aircraft factory. At this factory it was customary to use these tools for " scurfing" duralumin engine castings with rotary cutters. For polishing steel castings, such as centre bosses or " barrels" of large air-screws, they had three methods available. Method A (fig. 8) was to use the tool just described with stones and polishing buffs mounted on the spindle. The casting rested on the bench. Method B was to use a portable grinding wheel, driven by an electric motor incorporated in the body of the tool (fig. 9). In method $\mathrm{C}$ the casting was grasped in the hands, allowed to rest on the thigh, and applied to a large grinding wheel which was either belt-driven or fixed to the spindle of a powerful motor fixed on a bench mounting (fig. 10).

The conditions of method A were studied as follows. The acoustic spectrometer and crystal pick-up were used as before. The services of an experienced foreman from the polishing shop were provided. He was a righthanded man and always held the tool with his left hand in a pronated position in front near the " head," and with his right hand further back on the handpiece (fig. 11). The flexible drive cable passed along his right forearm. Cutting heads were tried out on a bulky block of cast duralumin, and grinding and polishing "bobs" or buffs on a large hollow steel casting. The machines could be run at any of three speeds, and readings were taken either with the tool idling or when working with a normal side-to-side stroke. While the tool was idling, the records remained steady enough for one reading only to be necessary; while it was working, the records were less steady, and the mean of three was always taken. The pick-up in its special mounting was strapped to the cylindrical handpiece directly under each hand in turn, at the level of the heads of the metacarpals. A few records were also taken from the back of the hand, the elbow, and the shoulder, and will be described later.

The following studies were made :

(a) of the vibration reaching the left and right hands;

(b) of that set up by various types of "heads" working at their optimum speeds on the usual material, that is, the cutters at medium speed (approximately 2,900 r.p.m.) on duralumin, and the stones or buffs at high speeds (while idling, approximately 8,300 r.p.m.) on the steel ;

(c) of the effect of different degrees of out-oftruth of the $\frac{1}{4}$ in. diameter projecting spindle on which the heads were mounted;

(d) of the effect on the vibrations of handpieces and cables which had worn to varying degrees:

(e) of the effect of wrapping round the handpieces various absorbent materials-namely, a $\frac{1}{2}$-in. thickness of sorbo sponge rubber, cloth-covered corrugated rubber from service respiratory equipment, a $\frac{1}{2}$-in. thickness of felt, balsa wood, and combinations of these.

While the tool was idling, it was possible to check the speeds with a simple revolution counter; while it was working it was necessary to approximate by using a "Strobotac" meter, relying on the stroboscopic effect of an intermittent beam of light. It was found that the motor was slowed during grinding operations, and that nothing like a steady speed can be maintained in practice, though as far as possible it was kept steady during the taking of the readings. Degrees of out-of-truth of the spindle were measured by a standard meter, reading to a thousandth of an inch. On advice from the operator we confined our studies to one speed for each "head," because he said that each had its optimum speed and should not be worked at any other.

Comparisons were next made between methods $\mathrm{A}, \mathrm{B}$, and $\mathrm{C}$, for working on the same steel casting. It was necessary not only to polish the rough surface of a casting, but often to remove as much as $\frac{1}{4}$ in. of excess metal as well. Where the shape of a casting is perfectly circular the excess can be removed quite simply by turning on a lathe ; at the corners this is impossible-hence the three alternative methods. The tool used in method B (fig. 9) is driven by an electric motor in the handle and is heavy, so the tool is suspended on a counterbalance weight allowing for movement in all planes. The handles are relatively thick, the grip needs to be less powerful, and the tool gives the impression of vibrating less than the one used in method A. In method C (fig. 10) the workman holds the casting to the wheel. The physical exertion involved is considerable, as it weighs perhaps $.50 \mathrm{lb}$. ; however, with practice the work can be done quickly and well. It must be emphasized that in this method of working a large casting is being applied to a 
relatively small wheel; this is very different from the procedure described by Agate, Druett, and Tombleson (1946), where castings of seldom more than 1 to $2 \mathrm{lb}$. were pressed against large, coarse wheels with the production of much vibration. With the method now being described, the vibration appeared to be very slight.

Finally, the rotary air turbine tools were considered. These were of two types : first, a heavy portable grindstone similar to the electrically driven one used in method $\mathrm{B}$ at the aircraft works ; secondly, a light, high-speed tool normally held in one hand, and used for fine polishing of metal parts. It was fitted with a small composition "head," and the tool, when idling, rotated at 60,000 r.p.m., but slowed considerably under a load. It was very similar to that described in Dart's and Peters' papers, though their machines revolved at some 25,000 r.p.m.

\section{The Results Recorded from Rotating Tools}

In interpreting the figures for rotating tools set out in Tables 3 and 5, certain difficulties are apparent. It is sometimes difficult to be certain which is the fundamental frequency due to shaft speed of the tool, for, as already explained, the motor was slowed up whilst grinding, and technical difficulties often prevented a count of the shaft speed at the moment when the record was being taken. By experience it has been possible to tell which " peak" figure in each of the tables is likely to indicate the fundamental vibration; it is usually a little below that calculated from the nominal speed of the tool. Secondly, when the vibration is slight the sensitivity of the apparatus must be high, so that interference from the alternating mains electricity supply may appear on the 50-cycles band, owing to the difficulty of earthing the apparatus effectively. Some of the values at 50 cycles in Tables 3 and 5 may, therefore, be untrue. Where this seems likely, particularly where there are no values visible for the harmonics derived from 50 cycles (which would otherwise be expected), the figure has been put in parentheses. The mains current by itself produced no harmonics above 50 cycles. Thirdly, it will be seen that there are often larger amplitudes at frequencies below the supposed shaft-speed fundamental. A likely explanation of this is that a slow periodicity is being set up, analogous to the periodicity set up if men march in step on a bridge. In this case it is not the tool vibrating alone, but a complex mechanical system made up of tool, muscles, and the bones and joints which are held rigid by these muscles. The aggregate mass of these tissues is usually larger than that of the tool; this is seldom the case with the larger piston-operated machines. It is very likely that this slow periodicity would alter according to the weight and physique of the operator. Unfortunately, we were unable to test this out experimentally. Whether the foregoing is the true explanation of the anomaly or not, the pick-up was nevertheless recording the vibration which was reaching the surface of the hands.

Table 3 compares the conditions encountered while investigating the rotary tool used in method $\mathbf{A}$ (fig. 8). Table 5 compares the other two methods $B$ and $C$; it depicts the vibration set up from the very high-speed air-turbine tool (fig. 12), and also the extent to which vibrations travel up the arm. For ease of comparison, Tables 4 and 6 have been constructed from Tables 3 and 5 , just in the same way as Table 2 was derived from Table 1, using "standard amplitudes." This time the greatest amplitude recorded has been included as well as the amplitude of the probable fundamental, and in brackets below each of these figures the frequency is shown. The highest point in the spectrum at which amplitudes of $1 \mathrm{~mm} ., 0.1 \mathrm{~mm} ., 10 \mu, 1.0 \mu$, and $0.1 \mu$ are still present is recorded, as in Table 2 . In most cases the fundamental is at 125 cycles per second, and most information is obtained from comparing the sizes of the fundamentals at this frequency. Amplitudes of $1 \mathrm{~mm}$. or more do not appear in any of the records from rotating tools, and from this point of view they compare very favourably with the extremely high amplitudes recorded from pneumatic hammers.

A : The Vibration Reaching Right and Left Hands.Comparing columns 19 and 20 , it will be seen that the left hand suffers much more than the right hand; the highest figure is over three times as high, and the fundamental is over twice as high, while amplitudes of a given size appear higher in the spectrum. Columns 22 and 25 show again that, when using the larger cutter on the duralumin block, the left hand absorbs much more vibration than the right hand, for, at the highest amplitude, which in this case is identical with the fundamental, the figure for the left is three times that for the right. The distribution at higher frequencies is, however, approximately the same. These two examples are but typical of many comparisons between right and left hands which we made in the course of the experiments ; in all cases the left hand absorbed more than the right.

$B$ : Comparison of Vibration Set Up by Different Tool "Heads."-Altogether records were made of more than 15 different types of " head." These consisted of buffs, grinding stones, mops, wire brushes, bristle brushes, and toothed cutters. Three examples have been selected, as these were in common use ; the others are omitted, from consideration of space. In all cases the left hand is considered. Column 20 refers to a silicon carbide stone (fig. 13), $1 \frac{3}{4}$ in. in diameter and $\frac{3}{4}$ in. deep, mounted on a $\frac{1}{4}$-in. spindle. This head is commonly used on steel with the tool running at top speed under load, that is, at approximately 7,500 r.p.m. Column 21 refers to a felt "bob," or "buff," 3 in. in diameter and in. deep, dressed with glue and emery (fig. 14) ; this is also used at top speed on steel, and gives a fine polish. Column 22 

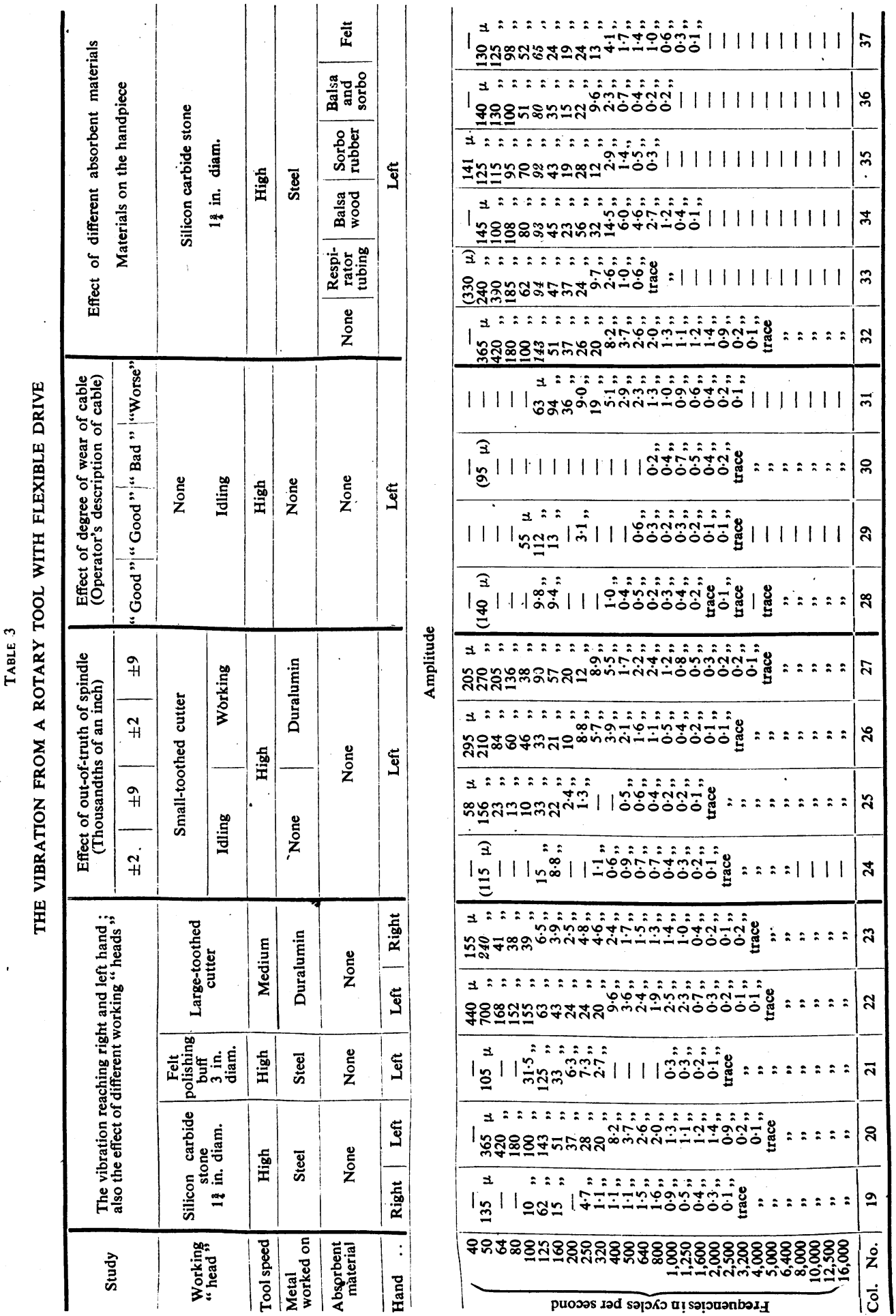


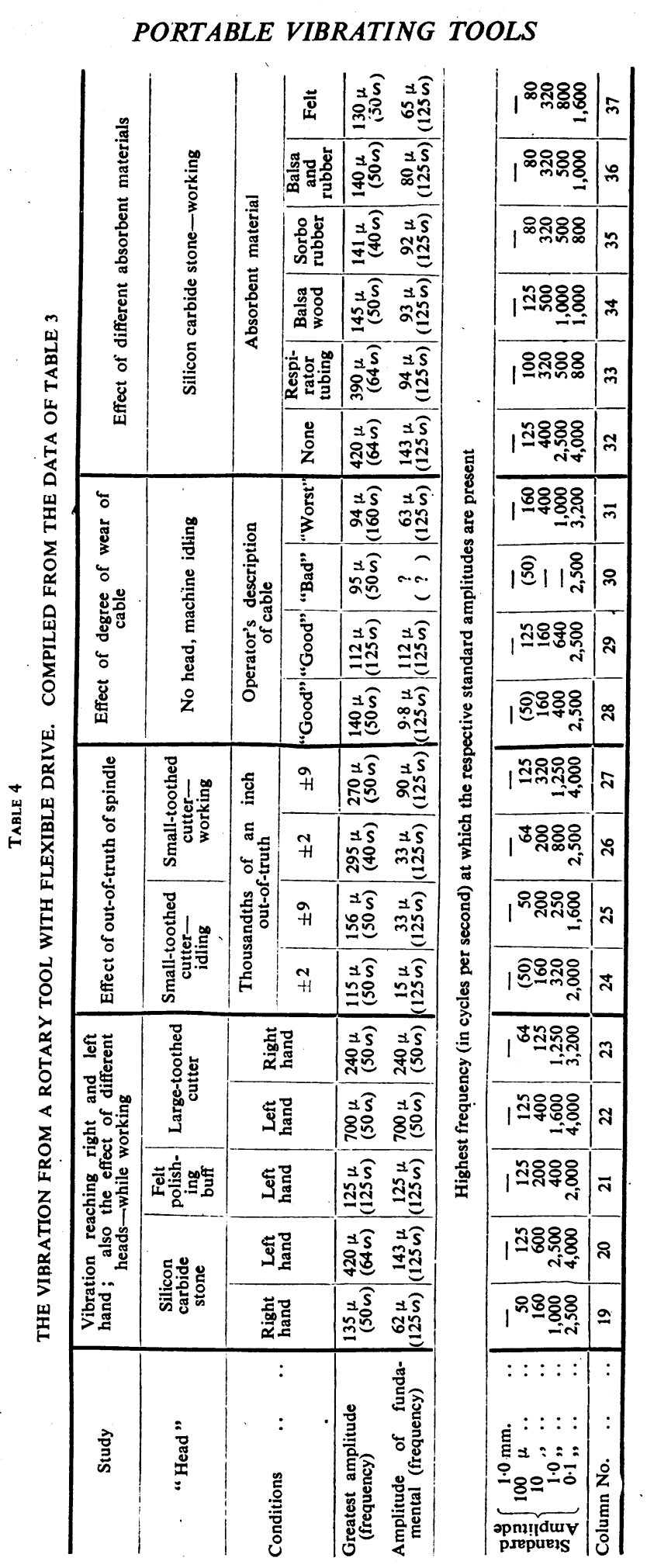

151

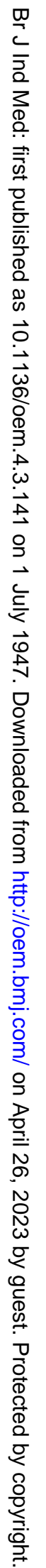


TABle 5

TOOL VIBRATIONS-VARIOUS STUDIES

\begin{tabular}{|c|c|c|c|c|c|c|c|c|c|c|c|c|}
\hline Study & \multicolumn{6}{|c|}{$\begin{array}{c}\text { Comparison of methods A, B, C for grinding and polishing } \\
\text { large steel castings for airscrews }\end{array}$} & \multicolumn{2}{|c|}{$\left|\begin{array}{c}\text { Vibration from a } \\
\text { high-speed rotary } \\
\text { tool for fine } \\
\text { polishing }\end{array}\right|$} & \multicolumn{4}{|c|}{$\begin{array}{l}\text { Transmission of vibration } \\
\text { up the arm }\end{array}$} \\
\hline Tool & $\begin{array}{c}\text { Method A : } \\
\text { flexible drive } \\
\text { tool (see } \\
\text { tables } 3 \\
\text { and 4) with } \\
\text { silicon carbide } \\
\text { stone }\end{array}$ & $\begin{array}{r}\text { Meth } \\
\text { elect } \\
\text { driven g } \\
\text { with } \\
\text { incorp } \\
\text { the 1 }\end{array}$ & $\begin{array}{l}\text { B : } \\
\text { ally } \\
\text { idstone } \\
\text { otor } \\
\text { ted in } \\
\text { dile }\end{array}$ & $\begin{array}{l}\text { Method C : } \\
\text { holding } \\
\text { casting } \\
\text { against } \\
\text { belt-driven } \\
\text { grinding } \\
\text { wheel }\end{array}$ & $\begin{array}{r}\text { Alter } \\
\text { tool } \\
\text { with me } \\
\text { air-c } \\
\text { portab } \\
\text { st }\end{array}$ & $\begin{array}{l}\text { tive } \\
\text { use } \\
\text { od } B \text { : } \\
\text { ven } \\
\text { grind- } \\
\text { e }\end{array}$ & & & $\begin{array}{l}\text { As for } \\
\text { cutting }\end{array}$ & $\begin{array}{l}\text { method } \\
\text { head on d } \\
\quad(\text { left a }\end{array}$ & $\begin{array}{l}\text { A, using la } \\
\text { luralumin } \\
\text { irm }\end{array}$ & $\begin{array}{l}\operatorname{arge} \\
\text { block }\end{array}$ \\
\hline Tool speed & $\begin{array}{l}\text { approx. } 7,500 \\
\text { r.p.m. }\end{array}$ & $\underset{\text { r. }}{\text { Nomin }}$ & 4,300 & & $\underset{r .}{\text { Nomin }}$ & $\begin{array}{l}\text { y } 5,400 \\
\text { n. }\end{array}$ & $\begin{array}{l}\text { Approx } \\
\text { while } \\
60,000\end{array}$ & $\begin{array}{l}\text { speed } \\
\text { idling } \\
\text { r.p.m. }\end{array}$ & & pprox. 2,9 & 900 r.p.m. & \\
\hline $\begin{array}{c}\text { Special } \\
\text { conditions }\end{array}$ & $\begin{array}{l}\text { Left } \\
\text { hand }\end{array}$ & $\begin{array}{l}\text { Left } \\
\text { hand }\end{array}$ & $\begin{array}{l}\text { Right } \\
\text { hand }\end{array}$ & $\begin{array}{l}\text { Right or } \\
\text { left hand }\end{array}$ & $\begin{array}{l}\text { Left } \\
\text { hand }\end{array}$ & $\begin{array}{l}\text { Right } \\
\text { hand }\end{array}$ & $\begin{array}{c}\text { Right } \\
\text { index } \\
\text { finger, in } \\
\text { "pencil- } \\
\text { holding", } \\
\text { grip at } \\
\text { nose of } \\
\text { tool }\end{array}$ & $\begin{array}{l}\text { Right } \\
\text { hand on } \\
\text { pistol } \\
\text { grip at } \\
\text { back of } \\
\text { tool }\end{array}$ & $\begin{array}{l}\text { Record- } \\
\text { ing from } \\
\text { tool } \\
\text { hand- } \\
\text { piece }\end{array}$ & $\begin{array}{l}\text { Record- } \\
\text { ing from } \\
\text { skin of } \\
\text { back of } \\
\text { hand }\end{array}$ & $\begin{array}{l}\text { Record- } \\
\text { ing from } \\
\text { skin over } \\
\text { ole- } \\
\text { cranon }\end{array}$ & $\begin{array}{l}\text { Record- } \\
\text { ing } \\
\text { from } \\
\text { skin } \\
\text { over } \\
\text { acro- } \\
\text { mion }\end{array}$ \\
\hline
\end{tabular}

Amplitude

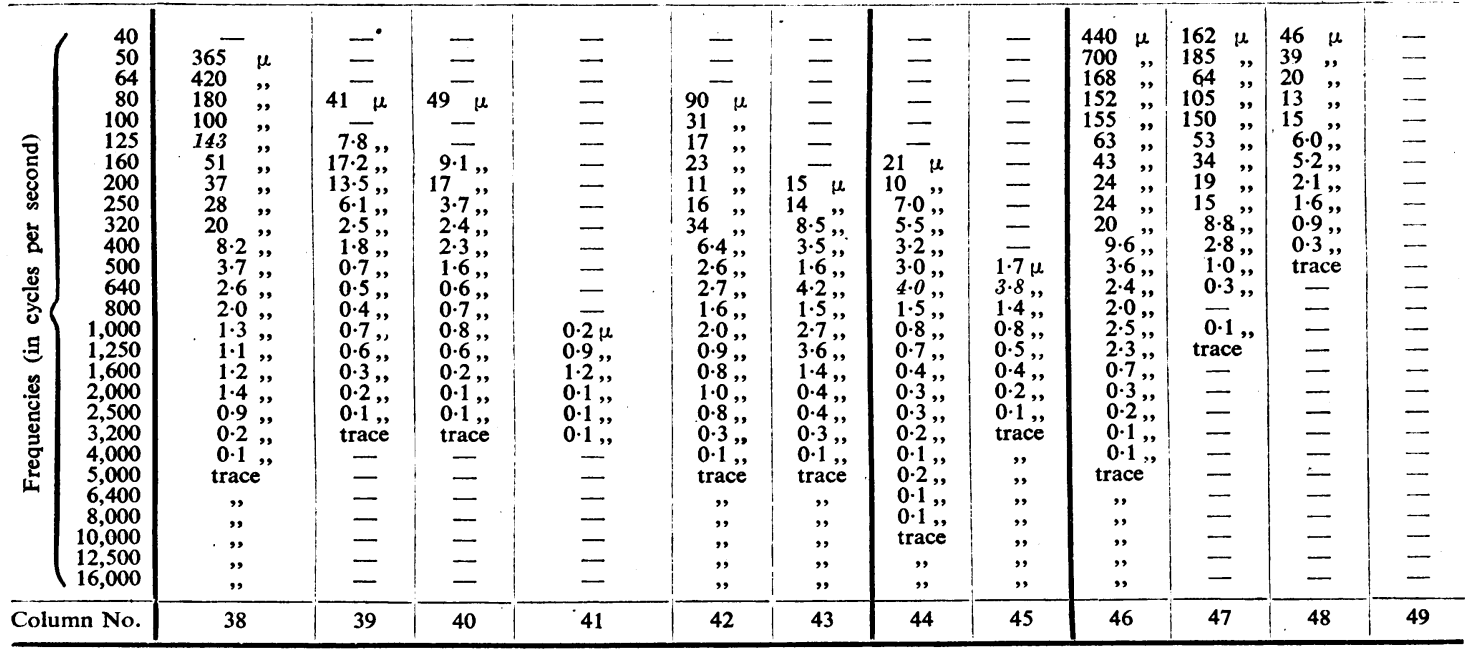

refers to a large pear-shaped steel cutter (fig. 15) with some 16 spiral cutting edges. This sort is used for cutting or "burring" excess metal from the duralumin block. It is used at medium speed, that is, at approximately 2,900 r.p.m. At this speed the teeth are least likely to get choked, and most power is available for cutting, for the operation is the heaviest for which this type of rotating tool is used. The fundamental will, in column 22, be seen coinciding with the highest amplitude at 50 cycles. When columns 20,21 , and 22 are compared, it will be seen that the felt bob causes least vibration. The cutter causes almost five times as much at the fundamental, although the frequency of that fundamental is lower. The silicon carbide stone occupies an intermediate position. The polishing buff causes less vibration at the higher end of the spectrum, but in this respect the stone and the cutter are nearly equal (cf. columns 20 and 22).
C: The Effect of Different Degrees of Out-of-Truth of the Spindle.-It is the usual practice, with the make of tool we were investigating, for the various heads to be mounted on a spindle $\frac{1}{4}$ in. in diameter. This spindle is $1 \frac{1}{2}$ to 2 in. long, of which 1 to $1 \frac{1}{2}$ in. projects from the chuck. As the spindle is so thin, it is easy to bend it by hitting the head of the tool inadvertently. Records were taken using a small cutter at high speed and recording from under the left hand. In the first case (columns 24 and 26) the spindle was adjusted to be as straight as possible and was, in fact, \pm 2 thousandths of an inch out of truth. In the other case it was given a knock and was \pm 9 thousandths of an inch out of truth (columns 25 and 27). Columns 24 and 25 refer to the tool while idling, and 26 and 27 to the tool while working. In each case it will be seen that the spindle which is \pm 9 thousandths of an inch out of truth causes a considerably higher fundamental than the other, for, when idling, it is twice 
TABLE 6

COMPILED FROM THE DATA OF TABLE 5

\begin{tabular}{|c|c|c|c|c|c|c|c|c|c|c|c|c|}
\hline \multirow[b]{2}{*}{ Tool } & \multicolumn{6}{|c|}{$\begin{array}{c}\text { Comparison of methods } A, B, C, \text { for grinding and } \\
\text { polishing large steel castings for airscrew }\end{array}$} & \multicolumn{2}{|c|}{$\begin{array}{l}\text { Vibration from a } \\
\text { high-speed rotary } \\
\text { tool for fine } \\
\text { polishing }\end{array}$} & \multicolumn{4}{|c|}{$\begin{array}{l}\text { Transmission of vibration up } \\
\text { the arm }\end{array}$} \\
\hline & $\begin{array}{l}\text { Method } \\
\text { A : } \\
\text { silicon } \\
\text { carbide } \\
\text { stone }\end{array}$ & \multicolumn{2}{|c|}{$\begin{array}{l}\text { Method B : } \\
\text { electrically } \\
\text { driven tool }\end{array}$} & $\underset{C}{\text { Method }}$ & \multicolumn{2}{|c|}{$\begin{array}{l}\text { Alternative tool } \\
\text { for method B : } \\
\text { air-driven } \\
\text { tool }\end{array}$} & & & \multicolumn{4}{|c|}{$\begin{array}{l}\text { As for method A : large cutting } \\
\text { head on duralumin block }\end{array}$} \\
\hline Conditions & $\begin{array}{l}\text { Left } \\
\text { hand }\end{array}$ & $\begin{array}{l}\text { Left } \\
\text { hand }\end{array}$ & $\begin{array}{l}\text { Right } \\
\text { hand }\end{array}$ & $\begin{array}{l}\text { Right or } \\
\text { left hand }\end{array}$ & $\begin{array}{l}\text { Left } \\
\text { hand }\end{array}$ & $\begin{array}{l}\text { Right } \\
\text { hand }\end{array}$ & $\begin{array}{l}\text { Pencil- } \\
\text { holding } \\
\text { grip, } \\
\text { right } \\
\text { index } \\
\text { finger }\end{array}$ & $\begin{array}{l}\text { Pistol } \\
\text { grip, } \\
\text { right } \\
\text { hand }\end{array}$ & $\begin{array}{l}\text { From } \\
\text { hand- } \\
\text { piece }\end{array}$ & $\begin{array}{l}\text { From } \\
\text { back of } \\
\text { hand }\end{array}$ & \begin{tabular}{|} 
From \\
skin over \\
olecranon
\end{tabular} & $\begin{array}{l}\text { From } \\
\text { skin over } \\
\text { acromion }\end{array}$ \\
\hline $\begin{array}{l}\text { Greatest ampli- } \\
\text { tude (frequency) }\end{array}$ & $\begin{array}{l}420 \mu \\
(64 \sim)\end{array}$ & $\begin{array}{c}41 \mu \\
(80 \sim)\end{array}$ & $\begin{array}{l}49 \mu \\
(80 \sim)\end{array}$ & $\mid \begin{array}{c}1.2 \mu \\
(1,600 n)\end{array}$ & $\begin{array}{l}90 \mu \\
(80 \sim)\end{array}$ & $(200 \sim)$ & $\stackrel{21 \mu}{(160 n)}$ & $\begin{array}{c}3.8 \mu \\
(640 \sim)\end{array}$ & $\begin{array}{l}700 \mu \\
(50 \sim)\end{array}$ & $\begin{array}{l}185 \mu \\
(50 \sim)\end{array}$ & $\begin{array}{l}46 \mu \\
(40 \sim)\end{array}$ & - \\
\hline $\begin{array}{l}\text { Amplitude of } \\
\text { fundamentai } \\
\text { (frequency) }\end{array}$ & $\begin{array}{l}143 \mu \\
(125 n)\end{array}$ & $\begin{array}{c}41 \mu \\
(80 \sim)\end{array}$ & $\begin{array}{c}49 \mu \\
(80 \sim)\end{array}$ & $\begin{array}{l}\text { Funda- } \\
\text { mental } \\
\text { not well } \\
\text { defined }\end{array}$ & $\begin{array}{c}90 \mu \\
(80 \sim)\end{array}$ & $(8 \overline{0 n})$ & $\begin{array}{c}4.0 \mu \\
(640 \sim)\end{array}$ & $\begin{array}{r}3.8 \mu \\
(640 \backsim)\end{array}$ & $\begin{array}{l}700 \mu \\
(50 \sim)\end{array}$ & $\begin{array}{l}185 \mu \\
(50 \sim)\end{array}$ & $\begin{array}{c}39 \mu \\
(50 \sim)\end{array}$ & - \\
\hline
\end{tabular}

Highest frequency (in cycles per second) at which the respective standard amplitudes are present

\begin{tabular}{|c|c|c|c|c|c|c|c|c|c|c|c|c|c|}
\hline 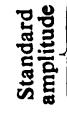 & $\begin{array}{c}1.0 \mathrm{~mm} . \\
100 \mu \\
10 \mu ", \\
1.0 ", \\
0.1 ",\end{array}$ & $\begin{array}{r}\overline{125} \\
400 \\
2,500 \\
4,000\end{array}$ & $\begin{array}{r}\overline{ } \\
\overline{200} \\
500 \\
2,500\end{array}$ & $\begin{array}{r}\overline{ } \\
\overline{250} \\
1,000 \\
2,500\end{array}$ & 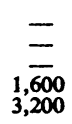 & $\begin{array}{r}\overline{80} \\
400 \\
2,000 \\
4,000\end{array}$ & $\begin{array}{r}\overline{ } \\
\overline{320} \\
1,500 \\
4,000\end{array}$ & $\begin{array}{c}\overline{ } \\
\overline{200} \\
1,000 \\
8,000\end{array}$ & $\begin{array}{l}\overline{ } \\
\overline{1,000} \\
2,500\end{array}$ & $\begin{array}{r}\overline{125} \\
400 \\
1,600 \\
4,000\end{array}$ & $\begin{array}{r}\overline{100} \\
320 \\
500 \\
1,000\end{array}$ & $\begin{array}{l}\overline{-} \\
125 \\
320 \\
500\end{array}$ & 二 \\
\hline Colun & nn No. & 38 & 39 & 40 & 41 & 42 & 43 & 44 & 45 & 46 & 47 & 48 & 49 \\
\hline
\end{tabular}

as great, and when working it is three times as great. Moreover, while idling it causes high amplitudes at most of the low frequencies, and most closely resembles the state of affairs while any tool is being used for heavy work. While idling the "standard amplitudes" (Table 4) are present to about the same height in the spectrum, but, while working, a spindle which is out of truth causes the "standard amplitudes" to appear higher than they otherwise would. After it had been used for burring purposes, it was found that the spindle which had been originally \pm 9 thousandths of an inch out of truth was now running more truly. A slender spindle, therefore, though liable to be bent when knocked, was fine enough to be straightened again by usage. An experienced man is normally in the habit of testing a spindle by feel and by eye, and adjusting it before use.

D : The Effects of Cables Worn to Varying Degrees.Various motors and cables were used. Tool operators say that, as a tool gets older, the cable makes more noise and becomes hotter according to the degree of wear. A man could therefore say that a cable was "good" or "bad" by its sound or temperature while running. This criterion was the only one which could be used for the comparison of old and new, good and bad cables. The handpieces were held as usual, the crystal was under the left hand, and the tool was run at high speed, with no " head" in the chuck. Since the tool was idling it could be held with a light grip. This may explain the somewhat high values present in columns 28 to 31 , values which would have been lower if the operator had had to exert his full muscular power.
It will be seen from columns 28 to 31 that there is little or no correlation between the vibration reaching the hand and the way in which a man describes his cable; for instance, column 29, which refers to a "good" cable, shows a higher fundamental than column 31, which was described as the "worst possible" cable. The values at 50 cycles in columns 28 to 30 must be considered as suspect, for the reasons already given.

$E$ : The Effect of Various Absorbent Materials Wrapped Around the Handpiece.-For this purpose the silicon carbide stone used for the initial experiment (column 20) was again used at high speed, working on steel, and records were taken from under the left hand, as follows :

(1) with no absorbent material (column 32 identical with column 20);

(2) with a thickness of corrugated, cloth-covered rubber, as used for service respirators (column 33) ;

(3) with a hollow cylinder of balsa wood split in two, shaped to fit the handpiece and strapped on, its thickness being $\frac{3}{8}$ in. (column 34 );

(4) a thickness of $\frac{1}{2}$ in. sorbo sponge rubber (column 35) ;

(5) balsa wood laid on top of four narrow strips of the same $\frac{1}{2}$ in. sorbo rubber (column 36) ;

(6) a thickness of $\frac{1}{2}$ in. felt (column 37).

From these comparisons it will be seen that all the absorbent materials reduce the vibrations to some extent. The order of efficacy, when the amplitudes of the greatest 
vibration and in particular the amplitudes at the fundamental frequency are considered, are as follows : felt, balsa wood over sorbo rubber, sorbo rubber alone, balsa wood alone, and respirator tubing. The effect of the last three mentioned is almost identical. At best these materials reduce the figures by $\frac{1}{3}$ to $\frac{1}{2}$, compared with the initial reading in column 32. At the higher frequencies the respirator tubing and sorbo rubber have some damping effect, and for this purpose the order of efficacy appears to be : respirator tubing or sorbo, balsa wood plus sorbo, felt, and balsa wood alone. It must be recorded that in all cases the operator said that the handle was made too bulky by the absorbent material, and that he was less comfortable and less able to work accurately.

Tables 5 and 6, derived from the same data, are divided into three sections showing the results of three distinct studies.

(a) Comparison of the Vibrations from the Three Available Methods for Grinding and Polishing Large Steel Castings.-To compare the methods, large rough steel castings for airscrew bosses or "barrels" were ground to remove excess of metal. The details of each have already been described. The tool with the flexible driving shaft, as used for method A (fig. 8) has been the subject of the detailed analyses in Tables 3 and 4, but a set of readings from the left hand using a 13-in. silicon carbide stone at approximately 7,500 r.p.m.-typical conditions for doing this work - is included (column 38) to make direct comparison easier. This column is identical with column 20 of Tables 3 and 4 .

When method B (fig. 9) was being considered readings were taken from under both left and right hands (columns 39 and 40). The figures in each of these columns are very similar, but it is surprising to find that at the fundamental frequency a slightly larger amplitude was found for the right hand than for the left, although the left hand was on the front half of the handle nearest to the grinding wheel. This anomaly may perhaps be explained by the fact that the tool was suspended at its midpoint by a wire from the counterbalance weight, which might therefore act as a fulcrum and transmit an unusual quantity of vibration back to the right hand. This tool nominally worked at 4,300 r.p.m. driven by an electric motor, but the fundamental frequency of 80 cycles per second suggests that the real speed is nearer 4,800 r.p.m. An alternative tool which could be used for method $B$, that is, one worked by an air turbine at a nominal speed of 5,400 r.p.m. was also studied, and is the subject of columns 42 and 43 , which deal with the right and left hand respectively. This tool was held in the same way, but without a counterbalance weight; it will be seen that the vibration reaching the left hand was much more than that reaching the right, but that for the former the size and range were very similar to columns 39 and 40 .

In method C (fig. 10) the pick-up was placed directly on the steel casting under the right and left thumbs, but the two sets of readings are almost identical, and are included as one set in the tables (column 41).

Comparing the three methods it is easy to see that method $\mathrm{C}$ produces incomparably less vibration than method A. It cuts out all vibration whatsoever up to
800 cycles per second, and from 4,000 cycles upwards. Both hands are subjected equally to its very small vibration. It should be noted that the highest amplitude is $1 \cdot 2 \mu$ at 1,600 cycles, and this is the same value as for method $A$ at this frequency ; from other points of view, however, there is no comparison between them. When method B is considered it is apparent that its highest values of 41 to $49 \mu$ at 80 cycles are only about one-fourth of the equivalent value for method A. Up to 64 cycles and above 3,200 cycles no vibration is encountered. Thus, method B is a marked improvement over A, but it is not so good as method $C$.

(b) The Vibration from Very High-speed Rotary Tools.This tool (fig. 12) was similar to the one described by Dart (1946) but worked at the higher nominal speed of 60,000 r.p.m. when idling. It is likely that its speed dropped to about 38,000 r.p.m. during our experiments owing to being slowed by the friction, but this could not be accurately checked. The tool is $1 \frac{1}{2} \mathrm{lb}$. in weight, and is easily held in the fingers of the right hand alone near the point, like a pencil ; alternatively, it can be held with the right hand gripping at the back, pistol-grip fashion, and with the fingers of the left hand guiding the point. Our records were made from the right hand with both these grips, using the tool for polishing small pieces of steel. It will be seen that when they were at the point of the tool (column 44), the fingers absorbed much more than when they were on the pistol-grip (column 45). . In the latter position the disturbance was negligible : in the former the fingers encountered no vibration below 160 cycles per second, but the value of $21 \mu$ at this level is fairly large for such a frequency. In general, large amplitudes at low frequencies were not met with ; nevertheless there is appreciable vibration at the top end of the frequency scale. It reaches at least to 8,000 cycles per second, that is, to a higher frequency than the vibration for any kind of rotary tool.

(c) The Transmission of Vibration up the Arm.-Tables 5 and 6 finally show a set of four records, columns 46 to 49, which were taken from various points up the left arm. They indicate what is likely to take place when any rotary type of tool is held in the hands. They were done on the suggestion that the damaging force might be acting more proximally than distally on the nerves or vessels. It is known already that a proximal lesion of an artery of the arm can give rise to intermittent local arterial spasm at the palm or fingers. The flexible drive tool was again used, under the worst conditions, namely-using a largetoothed cutter at medium speed while doing heavy work on a duralumin block. Column 46 records the state of affairs at the palm of the hand, and is identical with column 22 of Tables 3 and 4 . When next the pick-up was strapped with adhesive tape to the skin on the back of the hand, the figures (column 47) were all much reduced and no vibration was in evidence above 1,600 cycles. From the skin over the olecranon the pick-up detected even less amplitude at each frequency, and the damping action of the tissues had more effect on the higher frequencies than on the lower, with the result that in column 48 the highest amplitude appears, not at 50 cycles as previously, but at $\mathbf{4 0}$ cycles. A pick-up placed 
on the tip of the acromion detected no transmitted vibration whatever. It must be admitted that transmission of vibration across interfaces from tissue to tissue may affect its nature : there would be many such interfaces in recording vibration from far up a human arm, but it was outside the scope of our present work to consider this further. The results in columns 46 to 49 at best indicate a tendency.

\section{Discussion}

Study of the 49 columns makes it clear that the vibrations are complex in all cases, and that widely different methods of working can set up very similar conditions. Frequencies of the order of 1,000 cycles per second appear in nearly every column, and these seem to be related to the audible metallic " ring" of the metal of which a tool is made or of the metal being struck or ground. It is conducted back to the hands. Some simple experiments, such as striking a piece of metal on to which a pick-up had been placed, strengthen this view.

In order to detect any relationship between the characteristics of a vibration and the clinical effects caused by the tool in question, it is best to summarize those effects.

There is no certain evidence that Raynaud's phenomenon has resulted from using large road rippers, nor perhaps from somewhat lighter tools like coal picks. Extended inquiry might reveal occasional cases, but the numbers are probably not of practical significance. It has been suggested that navvying and the use of road rippers depend on casual labour, and that the men are, therefore, not exposed to hazard long enough for circulatory disturbances to appear. Rock drilling, by contrast, is far from a casual occupation, yet it leads to little trouble. These tools just mentioned are all large and used intermittently, and usually they work pointing downwards. Again, Raynaud's phenomenon has not yet been shown to result from using portable electric grindstones, as described above for method B. Those few men at the aircraft works who held the castings against the wheels as in method $\mathrm{C}$ likewise denied all knowledge of it. It has not occurred from the use of very light, highspeed tools. Finally, Hunter and others (1945) write of 12 men who used scaling hammers, and not one had contracted circulatory lesions, in spite of four of them having used such tools for over 20 years. This is surprising in view of the size of the vibration reaching the left hand (column 17); and if the phenomenon appears later in boiler scalers it must surely affect mainly the left hand. The lightness of the tool they use may be of significance, for the grip would therefore be light.

Positive evidence of Raynaud's phenomenon is reported from many quarters where the following tools are in use ; (1) riveting hammers and " holding up " tools: (2) pneumatic chisels or chipping hammers, which are used for fettling castings, caulking, stone dressing, etc.; (3) portable rotary tools with a flexible drive (Telford and others, 1945); and (4) large grindstones against which small castings are being ground (Agate, Druett, and Tombleson, 1945).

Comparing the foregoing clinical facts with experimental results, it is evident that a plainly visible vibration of huge size and of frequency below 40 cycles per second (column 1 ) is not likely to be responsible, or road rippers would have been a source of trouble. Nor is it likely that high-frequency vibrations of 1,000 cycles upwards are responsible, because method $\mathrm{C}$ produces no symptoms, even though the amplitudes (see column 41) in its own range (around 1,600 cycles) are just as high as those from any others of the rotating types of tool. The field may perhaps be narrowed even further, because the very high-speed tool (columns 44 and 45) produces vibration from as low as 160 cycles upwards without evidence of Raynaud's phenomenon ; but this argument must be accepted with caution, because if the amplitude at this frequency had been ten times as great (as it was in the case of the chipping hammers, see columns 2 to 7), there might then have been symptoms. Also, it must be remembered that Gerbis and others (1931) have suggested that vibration of 280 to 600 cycles per second caused vascular disturbances very rapidly, though we know nothing of the amplitudes involved. The evidence in general suggests that if any tool produces high amplitudes at the lower frequencies of, for example, 40 to 125 cycles per second, it is likely to produce Raynaud's phenomenon, particularly if it is in continuous use. Conversely, if a tool produces only high frequencies of, say, 600 cycles upwards, or it only produces small amplitudes (e.g. less than $100 \mu$ ) at the lower frequencies, it is not likely to cause Raynaud's phenomenon. Closer delineation is not yet possible, because there is still insufficient clinical evidence that tools which obey this last criterion have never produced the phenomenon. It is never safe to assume that there is no incidence of Raynaud's phenomenon from the use of a suspected tool until direct inquiry has been made. A man who suffers only slight disability may be reluctant to risk his livelihood by reporting his condition. A typical example of a tool which is a bad offender on clinical grounds is the flexibly driven rotary tool of method $A$ with a large cutter mounted on its spindle (column 22). Experimentally this produces small vibrations at the high frequencies, none below 40 cycles per second, and 
high amplitudes $(152$ to $700 \mu)$ between 40 and 100 cycles.

The use of this last-mentioned tool requires further discussion. The heads of the tool are freely interchangeable. In practice it is common for one workman to do several operations in succession, changing the " head" each time. It is consequently difficult to incriminate any particular one, as most men have used all the heads at different times. In a series as yet unpublished, 300 men were seen by one of the authors working with this type of tool, and two-thirds exhibited Raynaud's phenomenon. The incidence of lesions was highest in the left hand for the right-handed workers. This agrees exactly with the experimental findings (columns 19 to 23), because the left hand always received most vibration. It has already been shown that the degree of wear in the cable has little bearing on the matter, but that if a spindle is out of centre the vibration is proportionally increased. It is likely that a robust spindle which could not be bent by a knock, and high-quality bearings in the handpiece, would reduce the disturbance. But conversely a slender spindle, set in the first place out of truth, may become trued by heavy use. We have watched an intelligent operator armed with a vice, a spanner, and chalk, set a spindle true in order to minimize his discomfort, but it takes time and patience to do this. The main defect of this tool appears to be that it is too light for heavy cutting duty. The heavier the handpiece, the less would it oscillate to the inevitable vibration set up ; the likelihood of this is demonstrated by the behaviour of heavy and light castings respectively, when ground by hand against a mounted grinding wheel. Moreover, the heavier a handpiece, the more of the work would be done by its weight and the less by the exertions and power of grip of the operator. The speed of this tool makes no appreciable difference, save that the frequency of the largest amplitude tends to fall as the speed falls; the rest of the picture is little changed. The hardness of the metal worked upon is immaterial, as different cutters are used for different metals, and in this series the worst vibration resulted from cutting the duralumin, which is softer than steel.

The effect of absorbent coverings on the handpiece is limited. Their practical usefulness depends on their having small bulk in the hands of the operator and on their ability to stand wear and tear. It is certain that an increase in the thickness of the absorbent material does not have a proportional damping effect. Of the materials tried, a thickness of felt of $\frac{1}{2}$ in. reduced the amplitudes to $\frac{1}{2}$ or $\frac{1}{3}$ of their former values within the range of 50 to 125 cycles, but it was not so effective as some other materials in reducing higher frequencies. In this latter respect a layer of $\frac{1}{2} \mathrm{in}$. of sorbo sponge rubber or a sleeve of respirator tubing were about equally effective, but they were not very effective at the lower frequencies. Respirator tubing covered with cloth has proved itself to some extent capable of standing the wear and tear, but it is doubtful if any softer rubber would do so. If it is conceded that the most dangerous vibrations are at low frequencies and high amplitudes, felt coverings should be of more value than rubber, balsa wood, or respirator tubing.

Proof of the usefulness of any device to counter vibration can unfortunately only be obtained clinically if fresh workmen are employed and the work is done continuously under the new conditions for at least two years before the incidence of vascular disease is ascertained.

The preceding paragraphs refer to a tool, the use of which constitutes method A (fig. 8). It will be clear from columns 38 to 43 that method B (fig. 9) is an improvement, but that method C (fig. 10) is the method of choice if vibration is to be minimized. Where external surfaces of large castings are concerned, it is without doubt the most satisfactory method. But unfortunately it is more clumsy than other methods, and is not applicable to internal or complex surfaces, and certainly not to the burring of complex aero engine castings, for which method A seems to be almost indispensable. Nor is this method $\mathrm{C}$ satisfactory for polishing small castings of light weight; as the hazard under those circumstances has already been shown to be high. If metal castings could be mounted in lathes or milling machines and the burring and polishing were done purely by mechanical means, the problem of the vibration would be solved. Strenuous attempts to do this have already been made at more than one aircraft works.

Attention must turn again to the particular pistonoperated pneumatic tools which have been shown to produce Raynaud's phenomenon. These are the chipping hammers and riveting hammers. These clearly produce intense vibration (see columns 2 to 7 and 11 to 16). Some of these records, unfortunately, do not show the size of the fundamental, but, by inference from the nearest harmonics, it can safely be assumed that those concerned must be of the order of 2 or $3 \mathrm{~mm}$., and sometimes very much higher. Such figures are higher by far than any produced by rotating tools. Even though it appears from previous discussion that the frequencies below 40 cycles are little concerned with the pathological process, the values in columns 2 to 7 and 11 to 16 for the range 50 to 160 . 

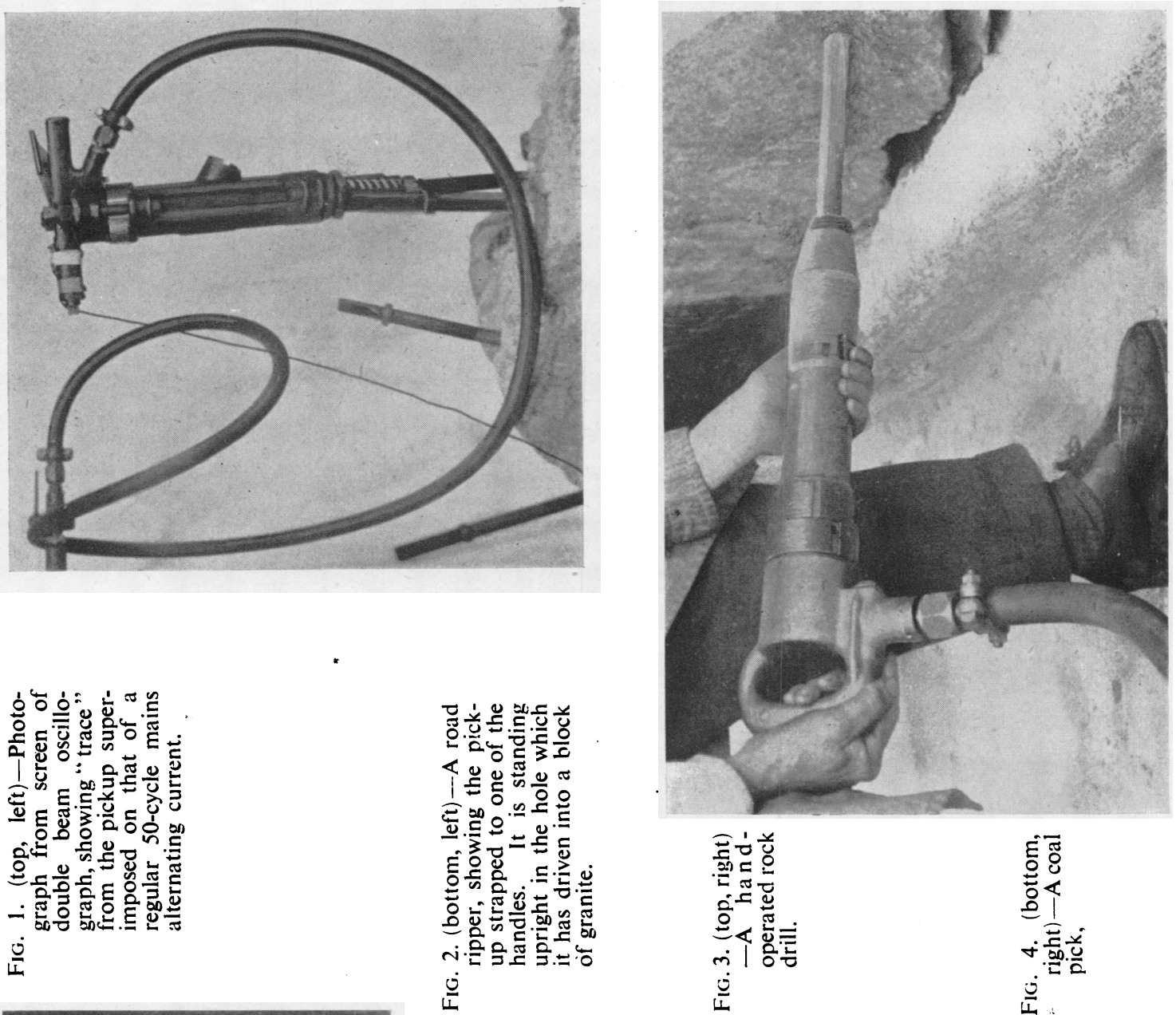
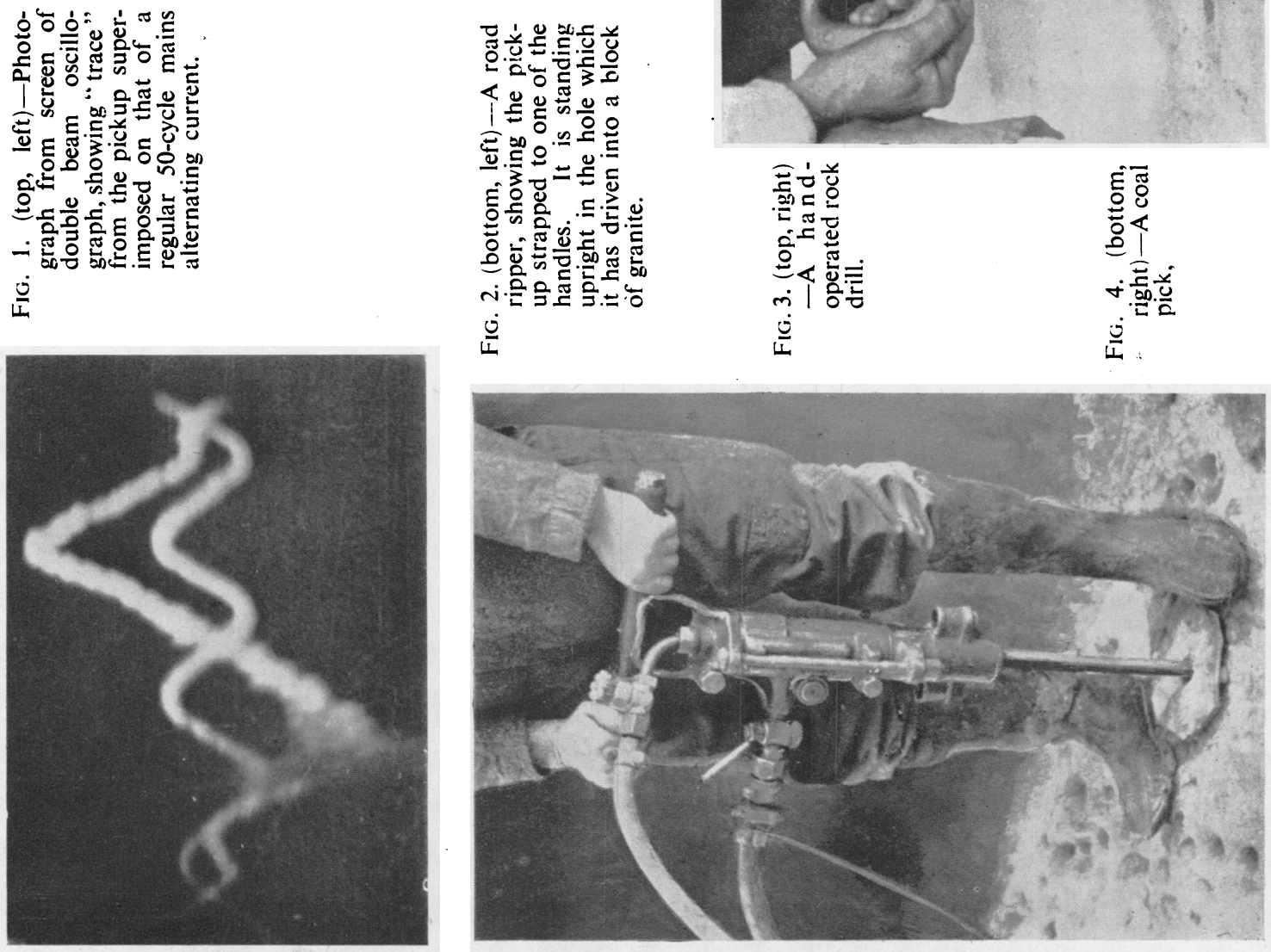


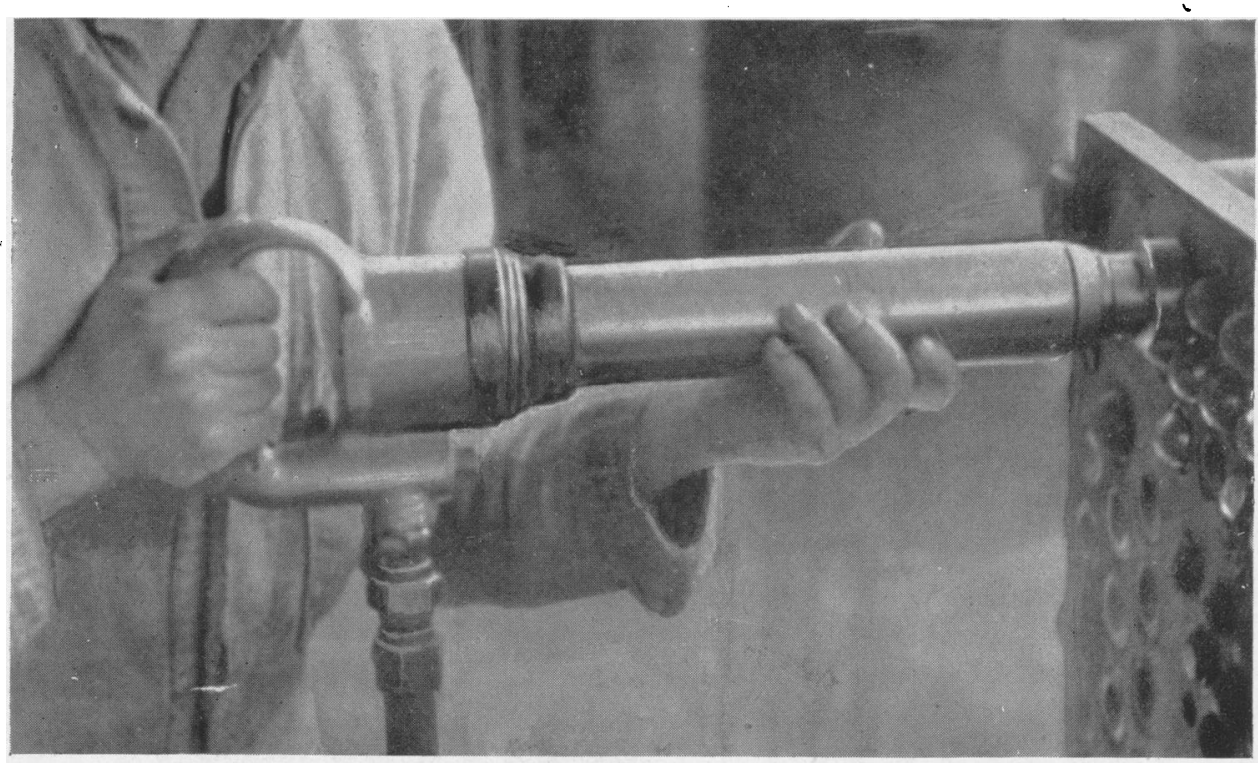

Fig 5.-A large riveting hammer.

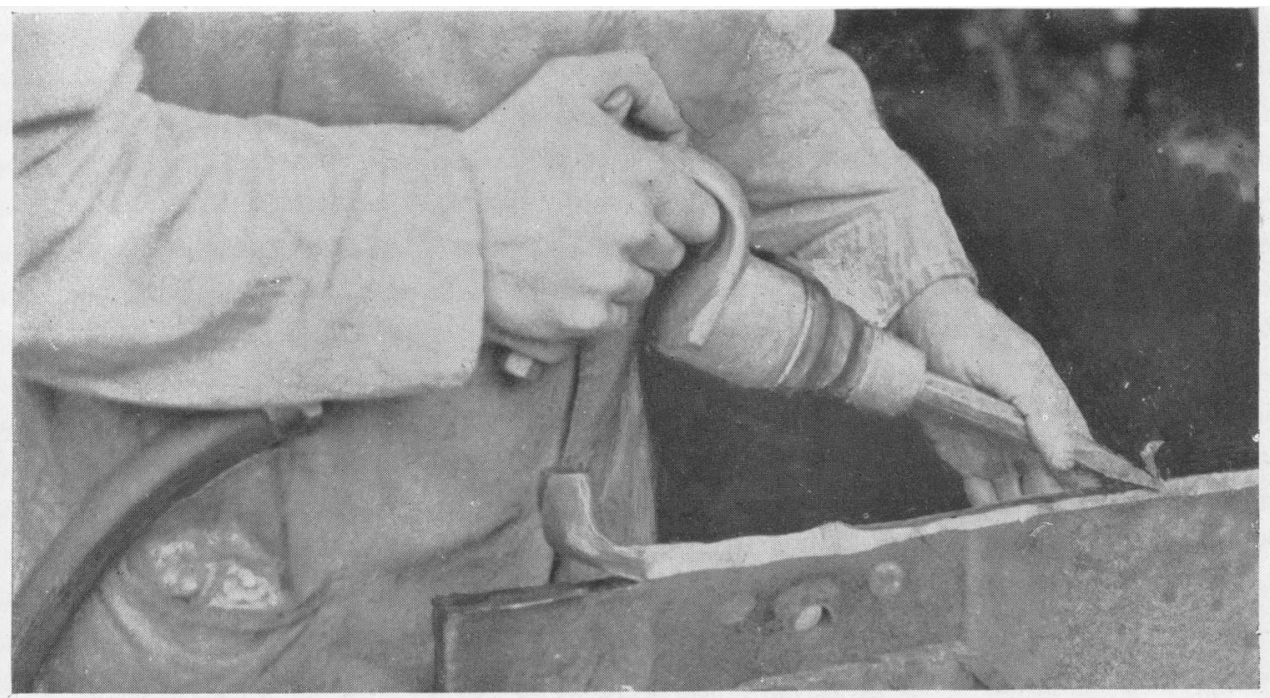

Fig. 6-A chipping hammer.

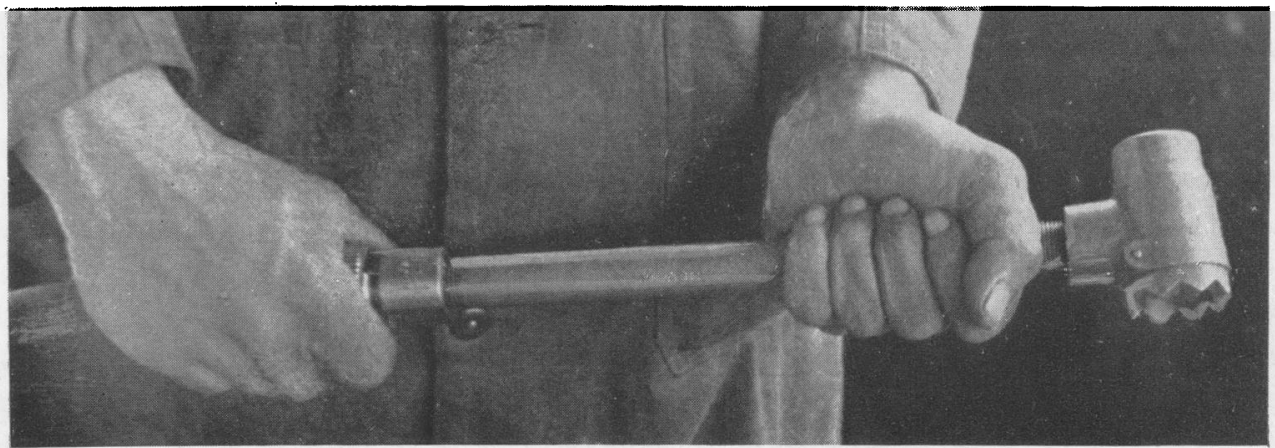

Fig. 7.-A scal.

ing hammer. 


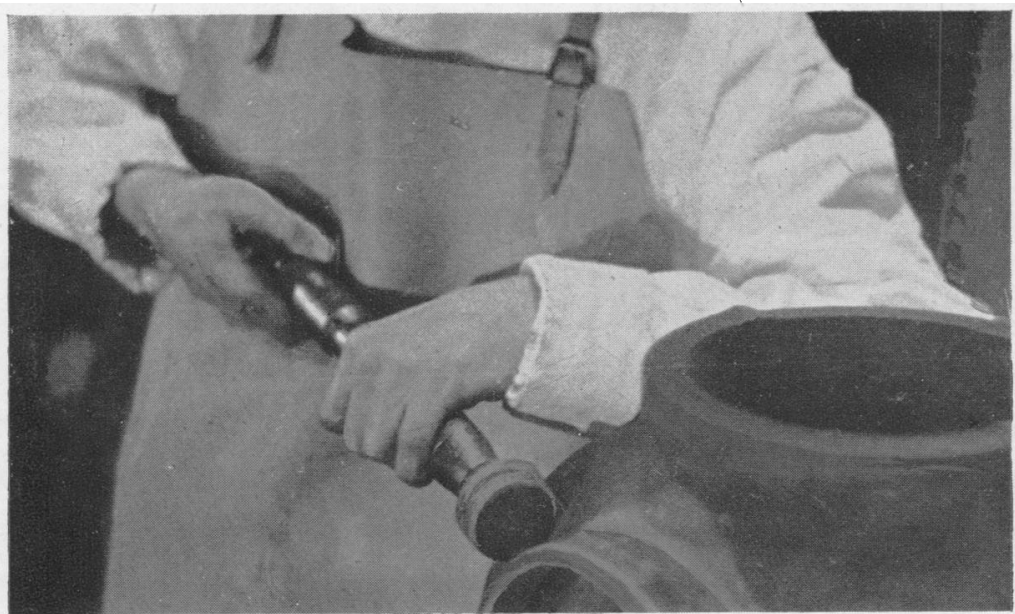

FIG. 8.- Method A for grinding steel castings. A small rotary grinding wheel is mounted at the end of a handpiece. Power is supplied from a motor (not shown) by means of a flexible drive.

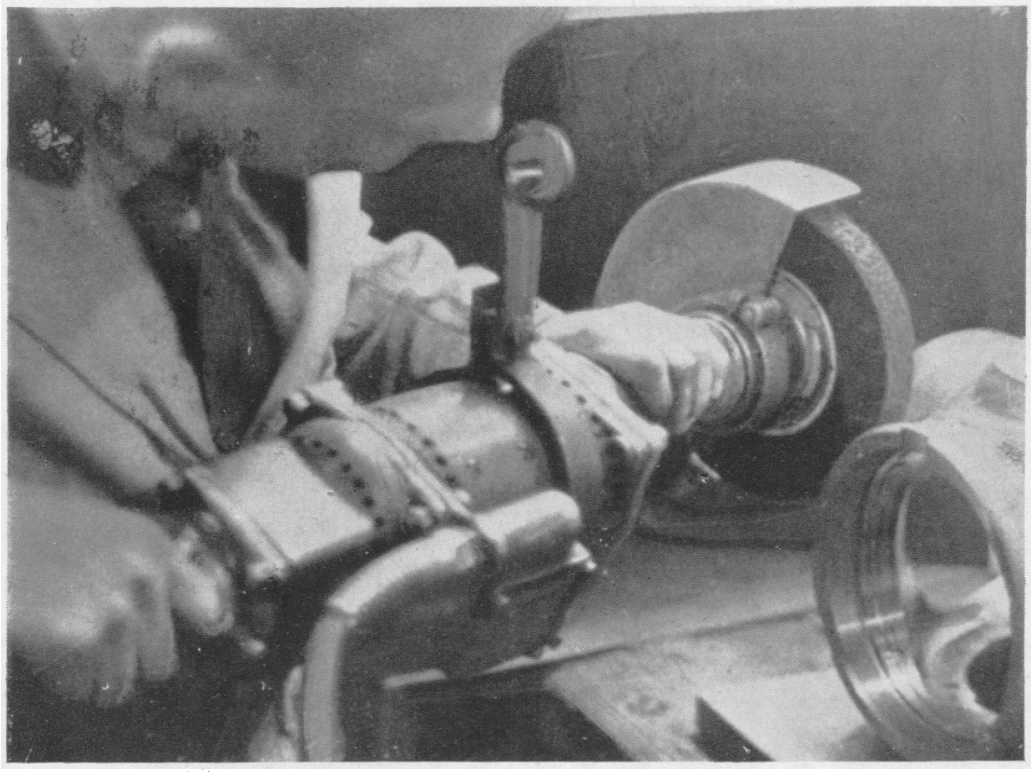

Fig. 9.-Method $\mathbf{B}$ for grinding steel castings. A portable grindstone, electrically driven by a motor, is incorporated in the handle. The weight is taken by a counter-balance weight.

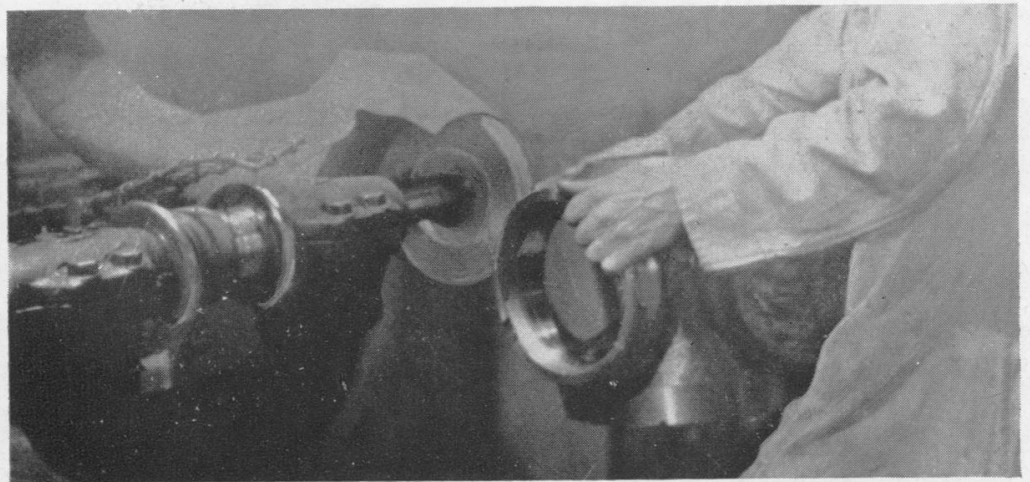

FIG. 10.-Method $\mathrm{C}$ for grinding steel castings. 


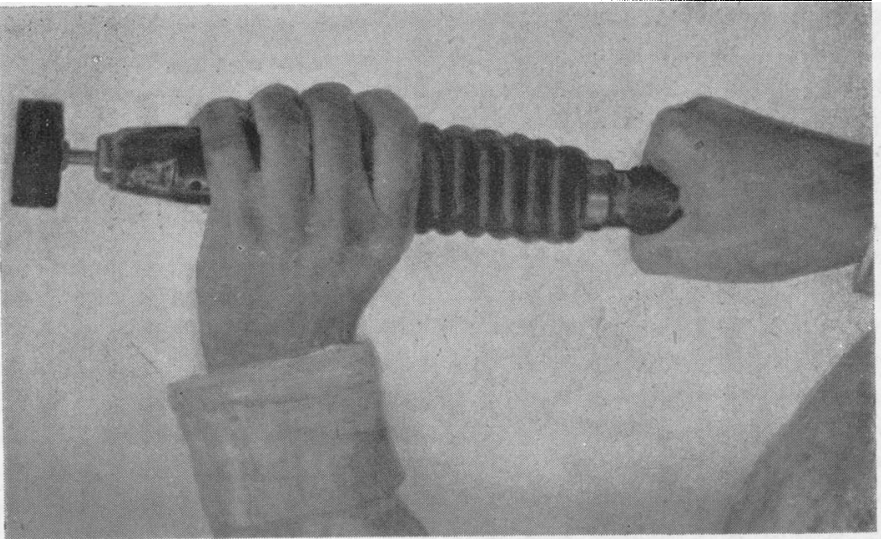

FIG. 11.-The grip typically used while grinding by method A. The handpiece shown here is covered by one of the experimental absorbent materials-a sleeve of cloth-covered respirator tubing made of corrugated rubber.

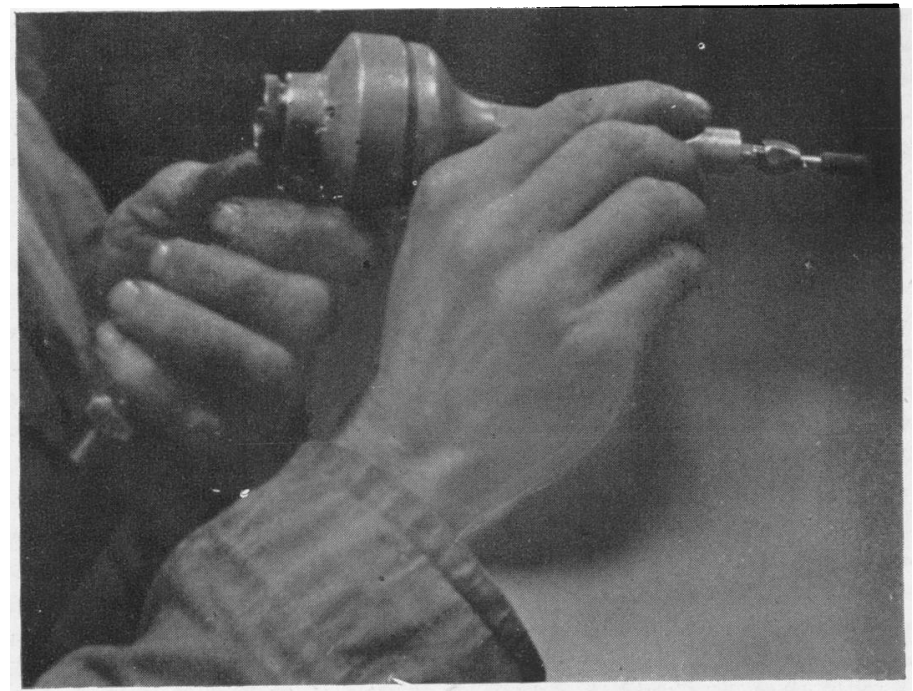

FIG. 12.-A light, portable polishing tool driven by an air turbine, and designed to rotate at 60,000 r.p.m. It is held like a pencil in the fingers of the right hand.

FIG. 14. (centre, right)-The 3-in. felt buff dressed with glue and emery, for use in method $\mathrm{A}$.

FIG. 15. (bottom, right)-The large-toothed steel cutter, for use in method A.

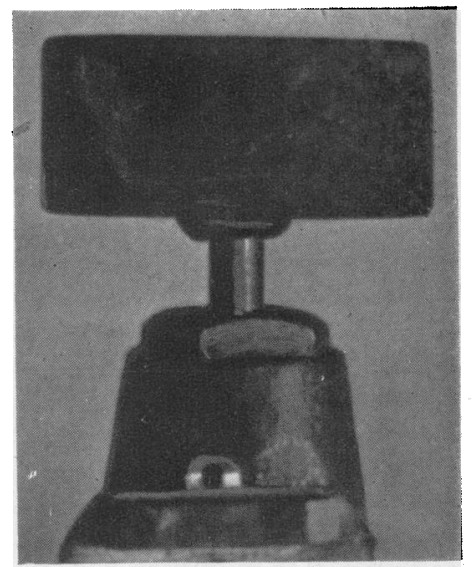

FIG. 13.-The $1 \frac{3}{4}$-in. silicon carbide grinding stone, for use in method $\mathrm{A}$.
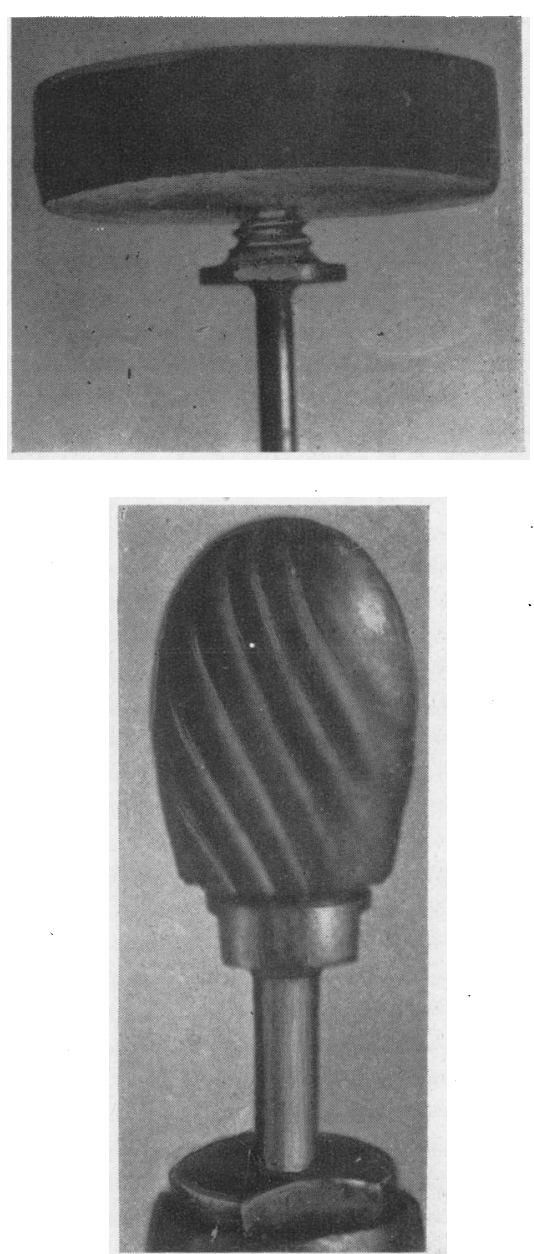
cycles are very high indeed. In all these columns it appears that the right hand is receiving more disturbance than the left. But many authors have stated that the left hand is the most affected by these tools. Hunter and others (1945) show that the left hand is more than twice as often affected as the right. This would appear to contradict the experimental evidence presented, but for the fact that, as has already been shown, the right hand receives a large component of vibration to and fro along the length of the tool, while the left receives the same component across the fingers, and also a secondary component at right angles to the first. In a sense, therefore, the left hand is receiving more than the right. These conditions only apply for a tool handled in the way in which riveting or chipping hammers are handled.

In the paper last quoted there is evidence to suggest that the greatest incidence of disease occurs when tools of 2,000 to 3,000 strokes per minute are used. We were unfortunately not in a position to compare tools of this range with any at higher and lower rates working on the same task. However, the vibration appears to be of the same complexity and about the same magnitude for all these tools, and from the figures it is difficult to conceive that their effects would be widely different in practice. The larger riveting hammer at 1,050 b.p.m., when used on hot rivets, seemed to produce a worse disturbance than the smaller at 1,700 b.p.m. On the other hand, the smallest chipping hammer at 6,000 b.p.m. caused much more vibration than the medium one at 3,500 b.p.m., when they were both used on the same piece of work. It appeared that this small hammer was being made to do heavier work than it was designed to do. As far as these hammers are concerned, it appears likely that the salient factor is not so much the tool speed as the heaviness of the work, expressed in terms of speed of working, exertion, and grip required. It may well be that the heaviest and most sustained work necessitates the use of tools at 2,000 to 3,000 b.p.m. When hot rivets are compared with cold, the harder cold metal causes a slight increase of disturbance for the right hand; but rivets of this size would never be hammered in the cold.

The high-speed tool we examined (columns 44 and .45) had a nominal speed of 60,000 r.p.m., which is up to six times that of the tools described by Dart (1946), but, in size, principle, and method of operation, they were similar. He states that such tools operate at 10,000 to 50,000 r.p.m.; though ours was even faster, the variations in speed during normal working were striking. Our tool running at an estimated working speed of 38,400 r.p.m. produced an amplitude of $4 \mu$ at the fundamental of 640 cycles per second, and its highest amplitude was $21 \mu$ at 160 cycles. Dart writes of a vibration of $80 \mu$ at 12,000 per minute, or 200 cycles per second, though whether this is the fundamental is not made clear. If, instead, it represents the highest recorded amplitude, his values are higher than ours but the frequency is comparable. Such a tool does not produce Raynaud's phenomenon, neither does it produce any vibration below 160 cycles per second. Dart states that of his total of 1,000 workers using this tool, there were some 11 per cent. with symptoms of the less objective type, namely, pain, numbness and stiffness, and signs of swelling, erythema, or cyanosis. There may, therefore, be some relationship between such a distinct syndrome and this type of vibration, for here in column 44 the rate for the main amplitudes is 160 cycles or above, with a spectrum reaching almost to the upper recordable limit. There is not a similar set of figures relating to the hand under normal working conditions anywhere else in our records. The vibration detected while using method $\mathrm{C}$ is of high frequency, true enough, but the amplitudes are all very small, and no comparable clinical syndrome has yet been shown to have resulted from using method $C$.

Dart lays some stress on the details of the grip of the fingers. He shows that the " pencil grip " may be the worst, and columns 44 and 45 demonstrate the difference between the disturbance produced while using the pencil grip and that while guiding the tool from behind. In our experience of grinding operations, an operator seemed often to change his grip, and it would have been impossible to incriminate any one grip in particular.

Negative Clinical Findings from a High-speed Tool. -An opportunity occurred at one stage in the work to put direct questions to ten people using a tool of the light, high-speed type. It had a nominal speed of 30,000 r.p.m. All the operatives, nine women and one man, denied any symptoms whatever that they could have attributed to their work. The relevant details are set out in Table 7.

The series was collected in the North of England in the spring of 1945 . The average duration of their employment at this work without symptoms was 2 years 8 months. Dart, however, writes that in a series of 109 cases with symptoms, the average duration of employment had been only 8 months, with a range of from 1 week to 30 months. Though our series is small and concerns a young age group, it is surprising that not a single case comparable with Dart's was discovered, especially as the mean of the working periods was longer than the longest working period he had recorded. If 
TABLE 7

TEN WORKERS WHO WORKED WITH A LIGHT HIGH-SPEED TOOL WITHOUT VASCULAR DISTURBANCES

\begin{tabular}{|c|c|c|}
\hline Worker No. & Age & $\begin{array}{l}\text { Employed with } \\
\text { this tool for- }\end{array}$ \\
\hline $\begin{array}{cc}1 & \text { (male) } \\
2 & \text { (female) } \\
3 & , " \\
4 & , \\
5 & , \\
6 & , \\
7 & , \\
8 & , \\
9 & , \\
10 & ,\end{array}$ & 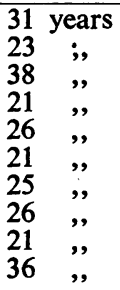 & $\begin{array}{l}5 \text { years } \\
4 ., " \\
4 \text { ", } \\
3 \text { ", } \\
3 \text { ", } \\
2 \frac{3}{4}, " \\
2 \text { year } \\
1 \text {," } \\
9 \text { months }\end{array}$ \\
\hline
\end{tabular}

an attempt should be made to reduce the vibration from light high-speed tools, our experiments suggest that a sleeve of sorbo sponge rubber or respirator tubing would probably be the most effective, because it is high frequency vibration of small amplitude which has to be combated.

\section{Practical Applications}

The following generalizations and suggestions for reducing harmful vibrations now seem to be justified.

1. Grinding, machining, and hammering processes should be as fully mechanized as possible.

2. Since portable tools are in many circumstances indispensable, the manufacturers of those tools should be urged to concentrate on modifications of design which will lessen vibration. They have in some cases shown themselves very willing to do so.

3. Vibrating tools should not be used on operations which are heavier than those for which they were designed.

4. The heavier a portable tool is in relation to the work in hand, the less it will vibrate.

\section{Concerning Pneumatic Drills, Picks, Hammers, and Chisels}

5. Methods might be sought for reducing the backwards thrust by bracing the tools against solid objects, or by mounting them on adjustable rigid beams. An adjustable portable stand is already made on which the weight of drilling tools can be taken for horizontal boring.

6. The weight of the tool might in some cases be taken by a suspended counterbalance weight. In some repetitive work this practice is already followed, as in locomotive boiler stay drilling and tapping.
7. The thrust might be divided to be taken on to both hands, or on to the thigh muscles, by extra handles.

8. Absorbent materials are not likely to be of much value.

\section{Concerning Methods of Grinding}

9. Light-weight tools with a flexible drive seem, on medical grounds, to be best avoided except for very light operations. There must be many conditions, however, in which their use is necessary.

10. The grinding method of choice, apart from any in which neither the work nor the tool is touched by hand, is that of holding castings against grindstones on fixed mountings, but this is true only for larger castings. Failing this method, the heavier the portable grinding equipment the better.

11. If tools with a flexible drive have to be used, they should be of heavier pattern than those at present manufactured, the spindle should be thick and rigid, and should run true on first-class bearings. The operator should be taught to correct a spindle which is not properly centred, and should be given the necessary tools to do this. He might with advantage alternate periods of heavy grinding with lighter polishing work.

12. Absorbent materials on the handpieces of tools with a flexible drive may be expected to have limited value only; if they are used, those which absorb low frequencies will probably be most effective (vide supra).

13. For light, high-speed tools, absorbent materials which reduce the higher frequencies should be the most effective (vide supra).

-Much of this work suggests, in conclusion, that the incidence of vascular disturbances does not depend solely on the character of the vibration. Grip is another likely factor in the production of local arterial spasm, but it could not be investigated by the present method. The most likely combination of provocative circumstances is vibration of fairly low frequency and large amplitude, coupled with the need to use an excessive grip over long periods. Further work on this aspect of the ætiology would be welcome.

\section{Summary}

Two clinical pictures which result from the use of vibrating tools are reviewed, with particular reference to the speeds of the tools, and the vibration frequencies which have hitherto been considered harmful. 
In the first clinical picture, Raynaud's phenomenon has been the predominant disorder, and it has arisen after the use of pneumatic hammers, from portable rotary grinding tools, and from grinding small metal parts by hand. In the second, the features are pain, numbness, stiffness, and swelling of the fingers, and the portable tool involved is used for light metal polishing and rotates at a high speed.

The complexity of vibrations from tools is discussed. Electrical methods of analysis of these, in terms of frequency and amplitude of the harmonics, have been used to take records from tools working under different conditions. Such records were taken from the following piston-operated tools : road rippers, pneumatic chisels (chipping hammers), coal picks, rock drills, riveting hammers, and scaling hammers. Others were made of the vibration set up in the use of a portable grinding tool driven by flexible drive. The effect of the work on right and left hands, the effect of various cutting and grinding "heads," degrees of out of truth, degrees of wear in the flexible drive, and of absorbent protective materials were determined. Three alternative methods for doing the same piece of grinding work were compared. The special characteristics of vibration from high-speed rotary tools responsible for the second clinical picture were demonstrated. Finally, a study was made of the transmission of vibrations up the arm.

By comparison with clinical data it appears probable that vibrations of large amplitude between the frequencies of about 40 and 125 cycles per second are concerned in producing Raynaud's phenomenon, and that tools which show none below 600 cycles are not likely to produce it. The lower limit may be below this, but the clinical evidence is still too scanty to allow of closer delineation. With rotary tools of the type with a flexible drive, the left hand is subjected to most vibration, toothed metal cutters cause most disturbance, and the vibration is greater the more out-of-true the heads are set. A worn flexible cable appears to have little aggravating effect. Of the absorbent materials tested, felt is probably the most effective for such a tool, though none has a very pronounced usefulness.

When the three alternative grinding methods are compared, that of holding castings against a grindstone mounted on a bench is likely to be harmless, provided that the castings are relatively large.

Very high-speed rotary tools produce a different type of vibration, namely, of relatively small amplitude and of high frequency, none being present below 160 cycles per second. This may account for the differences in clinical findings which have been observed from the use of such tools. A small series of ten workers is discussed, who complained of no symptoms whatever after they had used this type of tool for an appreciable time; this conflicts with the experience of other writers.

Piston-operated tools all seem to produce similar vibration spectra, and it is probable that pathological effects bear more relation to the type, arduousness, and uninterrupted nature of the work done than they do to a definite range of supposedly hazardous tool speeds. A number of suggestions is put forward for reducing harmful vibrations. The possible relationship between vascular lesions and the strength of the grip could not be studied by the methods used in these experiments.

We wish to thank the Director of the Department, Dr. Donald Hunter, for continued advice and encouragement, and Dr. Kenneth Perry for his valuable help. We are indebted to the Controller of the Post Office Research Station who lent the acoustic spectrometer, and to the Gramophone Company Ltd. for the loan of other apparatus. We gratefully acknowledge the kindness and unstinted help of Dr. D. R. Thompson of the De Havilland Aircraft Co help of Dr. D. R. Thompson of the De Havilland Aircraft Co. of that company. It is a pleasure to record our gratitude for the of that company. It is a pleasure to record our gratitude for the enthusiasm of Mr. A. Treve Holman and for the help he and the staff of Messrs. Holman Brothers Ltd. gave us. Our thanks are particularly due for the patience of Mr. Robinson and others who operated the tools during the experiments, and to Miss M. F. Daniel
for technical help.

\section{REFERENCES}

Agate, J. N., and Druett, H. A. (1946). Brit. J. industr. Med. 3, 159 .

3, and Tombleson, J. B. L. (1946). Ibid., 3, 167.

Bridge, J. C., and Middleton, E. L. (1925). Ann. Rep. H.M. Chief Insp. Fact., p. 66.

Brocklehurst, T. (1945). Med. Pr., 213, 10

Cummins, R. C. (1940). Irish J. med.Sci., 6s, 171

Dart, E. E. (1946). Occup. Med., 1, 515.

Edsall, D. L. (1918). Publ. Hlth. Rep., Wash., 33, 394

Gerbis, H., Gross, A., Meyer-Brodnitz, K.'F., and Robinson, J. (1931). Quoted by Teleky, L. "Occupation and Health Supplement," International Labour Office, Geneva. Sept., 1938.

Gurdjian, E. S., and Walker, L. W. (1945). J. Amer. med. Ass., $129,668$.

Hamilton, A. (1918). U.S. Department of Labor, Bureau of Labor Statistics, Bulletin No. 236, p. 53.

Hunt, J. H. (1936). Proc. roy. Soc. Med., 30, 171.

Hunter, D., McLaughlin, A. I. G., and Perry, K. M. A. (1945.)

Brit. J. industr. Med., 2, 10.

Leake, J. P. (1918). Publ. Hlth, Rep., Wash., 33, 379.

Leake, J. P. (1918). Publ. Hith, Rep., Wash., 33, 379. Health Supplement," International Labour Office, Geneva. Health Sup 1938 .

Sept., 1938.
McLaren, J. W. (1937). Lancet, 2, 1,296.

Middleton, E. L. (1930). Ann. Rep. H.M. Chief Insp. Fact., p. 119. Mills, J. H. (1942). Northwest Med., 41, 282.

Peters, F. M. (1946). Occup. Med., 2, 55 .

Rothstein, T., and others (1918). U.S. Department of Labor, Bureau of Labor Statistics, Bulletin No. 236, p. 67.

Seyring, M. (1930). Arch. Gewerbepath. hyg., 1, 359.

Teleky, L. "Occupation and Health" "Supplement, International Labour Office, Geneva. Sept., 1938.

Telford, E. D., McCann, M. B., and MacCormack, D. H. (1945) Lancet, 2, 359 .

Whitwell, W. T. (1945). Lancet, 2, 449. 